\title{
An Interspecies Investigation of Thyroid Plasma Hormone Concentrations, Histology, and Gene Expression
}

\author{
Emily A. Underwood \\ West Virginia University, eu0005@mix.wvu.edu
}

Follow this and additional works at: https://researchrepository.wvu.edu/etd

Part of the Environmental Indicators and Impact Assessment Commons, and the Environmental Monitoring Commons

\section{Recommended Citation}

Underwood, Emily A., "An Interspecies Investigation of Thyroid Plasma Hormone Concentrations, Histology, and Gene Expression" (2018). Graduate Theses, Dissertations, and Problem Reports. 3746. https://researchrepository.wvu.edu/etd/3746

This Thesis is protected by copyright and/or related rights. It has been brought to you by the The Research Repository @ WVU with permission from the rights-holder(s). You are free to use this Thesis in any way that is permitted by the copyright and related rights legislation that applies to your use. For other uses you must obtain permission from the rights-holder(s) directly, unless additional rights are indicated by a Creative Commons license in the record and/ or on the work itself. This Thesis has been accepted for inclusion in WVU Graduate Theses, Dissertations, and Problem Reports collection by an authorized administrator of The Research Repository @ WVU. For more information, please contact researchrepository@mail.wvu.edu. 


\title{
AN INTERSPECIES INVESTIGATION OF THYROID PLASMA HORMONE CONCENTRATIONS, HISTOLOGY, AND GENE EXPRESSION
}

\author{
Emily A. Underwood
}

THESIS

\begin{abstract}
Submitted to the Davis College of Agriculture, Natural Resources, and Design at West Virginia University
\end{abstract}

in partial fulfillment of the requirements for the degree of

\author{
MASTER OF SCIENCE
}

in

\section{WILDLIFE AND FISHERIES RESOURCES}

\author{
Patricia Mazik, Ph.D., Committee Chair \\ Vicki Blazer, Ph.D. \\ Amy Welsh, Ph.D. \\ A.B. Billings, MS
}

Division of Forestry and Natural Resources

Morgantown, West Virginia

2018

Keywords: Endocrine disrupting chemicals, chemicals of emerging concern, thyroid epithelial cell height, hypertrophy, colloid depletion, biomarker, deiodinase

Copyright 2018 Emily Underwood 


\begin{abstract}
An interspecies investigation of thyroid plasma hormones, histology, and gene expression
\end{abstract}

\title{
Emily A. Underwood
}

A high prevalence of endocrine disrupting chemicals (EDCs) in Great Lakes Areas of Concern (AOCs) has raised concerns as to the health and fitness of fish and wildlife. It is not well understood to what extent existing contaminants, many with continuing inflows into the environment, may impact fish populations. This study provides an initial characterization of thyroid endocrine-related effects in two indigenous fish species sampled from Great Lakes AOCs. Biomonitoring was conducted on a pelagic, top predator species, smallmouth bass (Micropterus dolomieu) and benthic, omnivorous brown bullhead (Ameiurus nebulosus) at 7 sites in spring and fall of 2012. Thyroidal endpoints, such as plasma hormone levels (plasma thyroid stimulating hormone-TSH, thyroxine-T4, and triiodothyronine-T3), thyroid histology (thyroid epithelial cell height and colloid depletion), and expression levels of thyroid-related genes (Thyroid receptor alpha-THR $\alpha$, Thyroid receptor beta-THR $\beta$, deiodinase type IDIO1, and deiodinase type II-DIO2) were measured in both species, and relationships between the endpoints were evaluated to see if associations exist between thyroid endpoints at multiple biological levels. Histological evaluation of the thyroid tissue indicated hyperstimulation (as indicated by increased thyroid epithelial cell height and partially depleted colloid) in smallmouth bass and brown bullhead sampled in the spring. Despite observed histologic alterations, changes in thyroid gland histology did not coincide with changes in concentrations of circulating thyroid hormones. However, gene transcript abundance of THR $\alpha$ was negatively correlated with TSH and T3 while levels of DIO2 were positively correlated with TSH and T3 in smallmouth bass, suggesting these genes are sensitive and stable indicators for thyroid status. The results demonstrate the importance of using a multi-tiered approach to evaluate the potential risks of EDCs on the teleost thyroid system, as well as the importance of choosing sensitive species and accounting for seasonality. 


\section{TABLE OF CONTENTS}

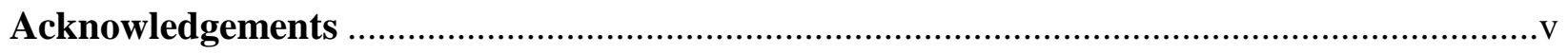

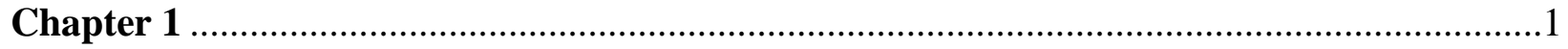

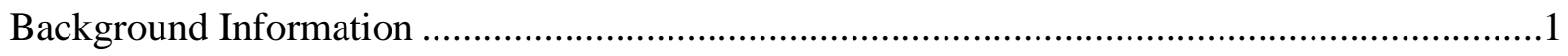

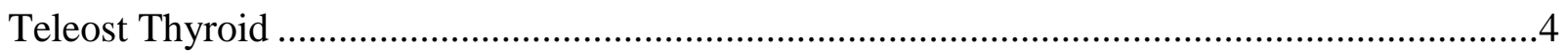

Hypothalamus-Pituitary-Thyroid Axis..............................................................................

Thyroid Hormone Actions in Fish ............................................................................................6

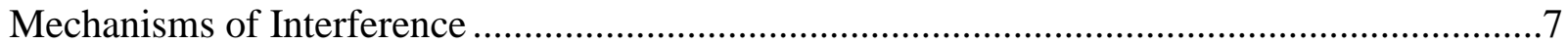

Thyroid Histological Biomarkers .....................................................................................

Thyroid Disruption Field Studies .....................................................................................

Objectives of the Current Study …………………………...............................................11

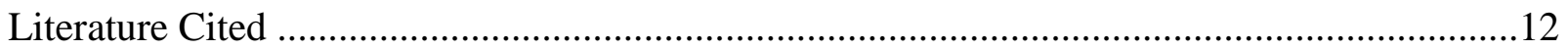

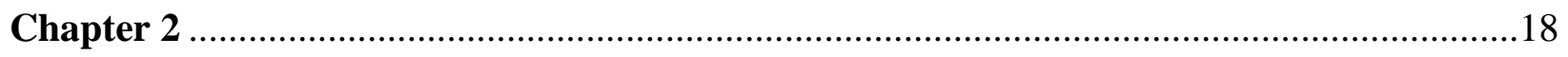

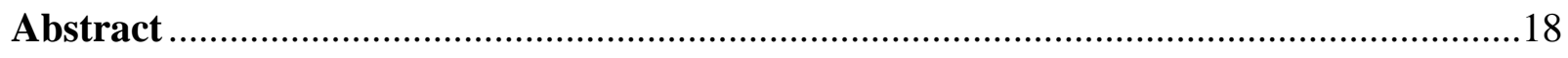

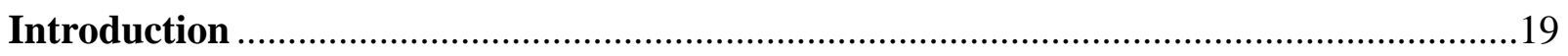

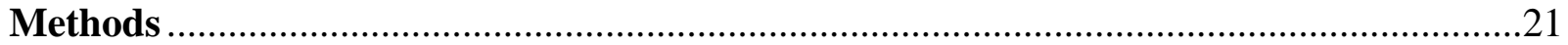

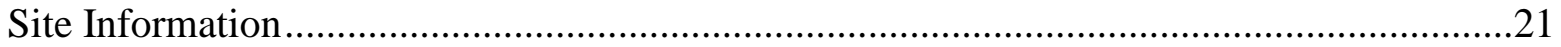

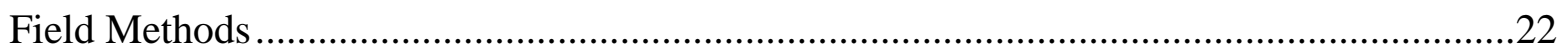

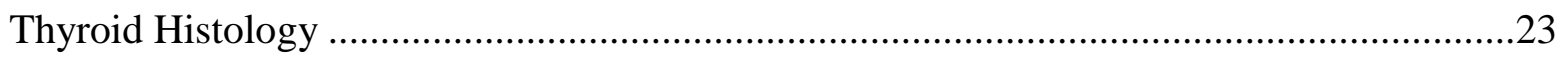

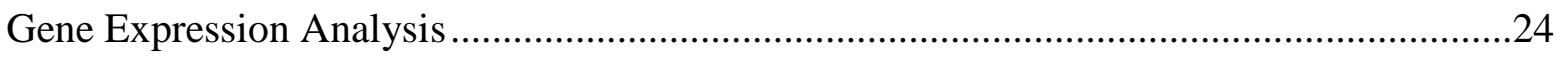

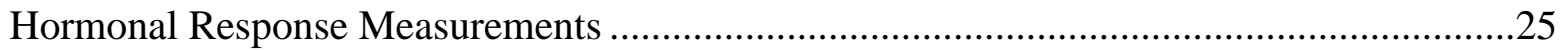

Thyroxine and Triiodothyronine ……………………….............................................25

Thyroid Stimulating Hormone …………………………........................................2

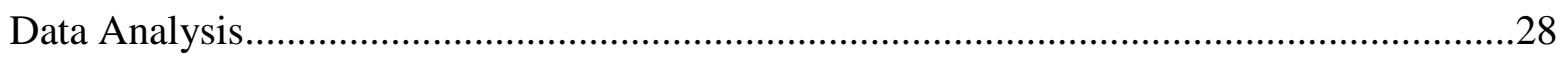

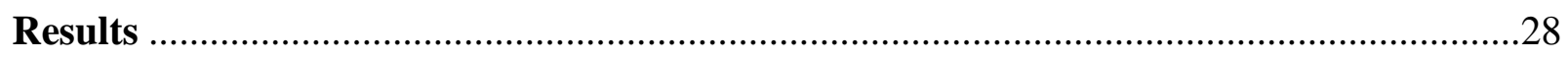

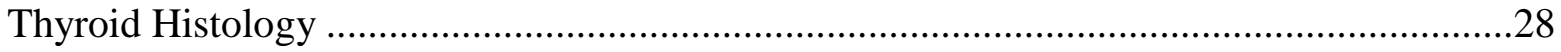

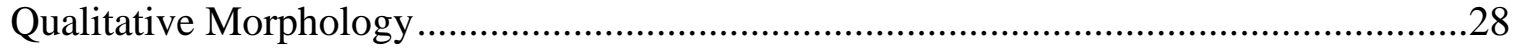

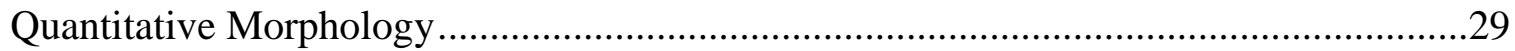

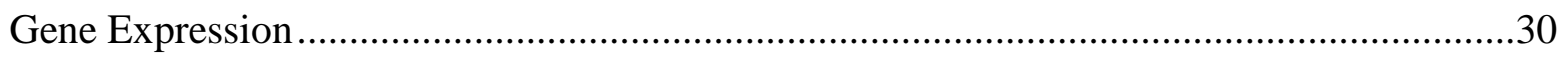

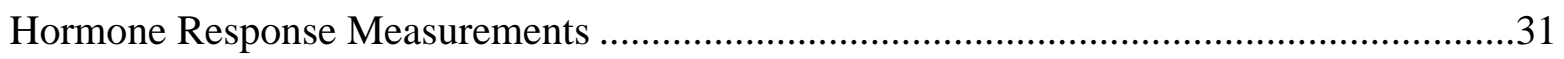

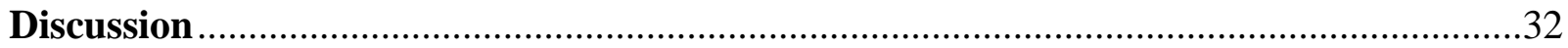




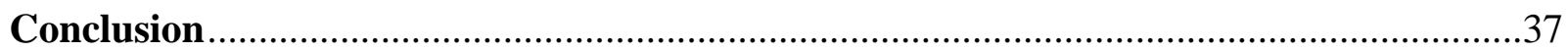

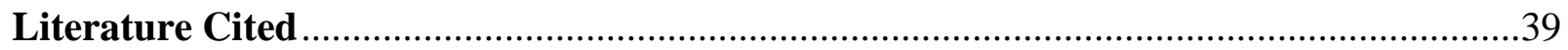

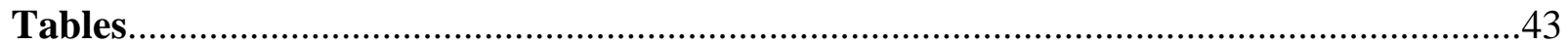

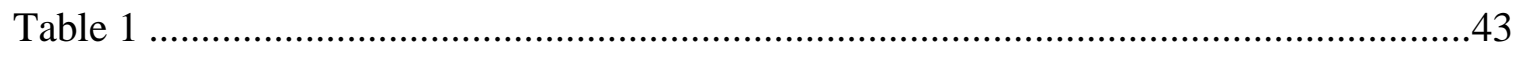

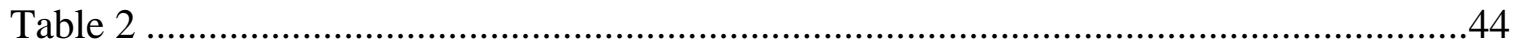

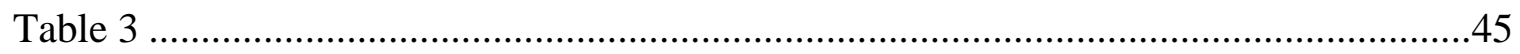

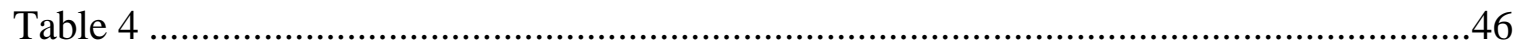

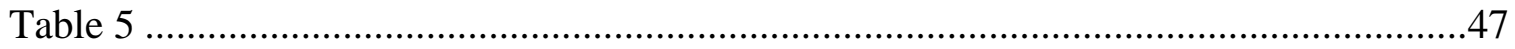

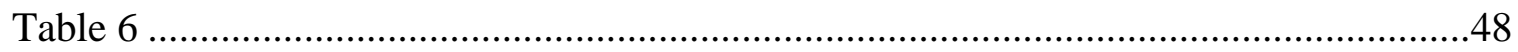

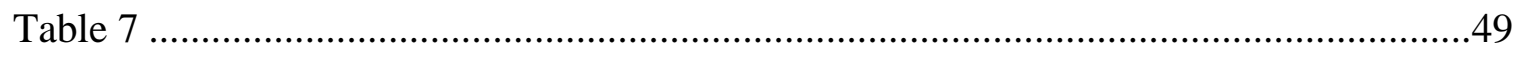

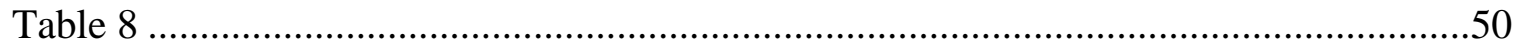

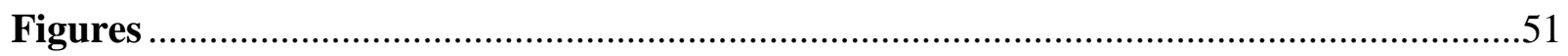

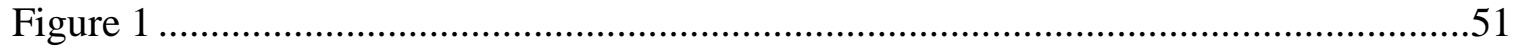

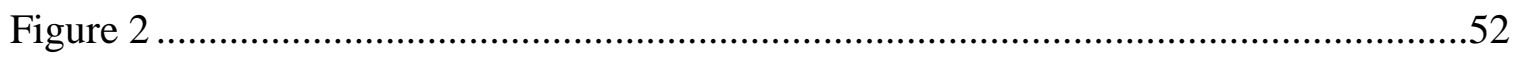

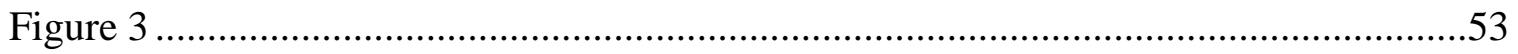

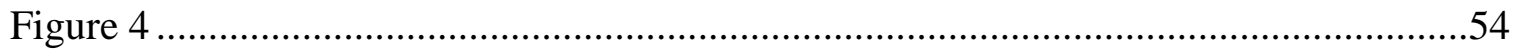

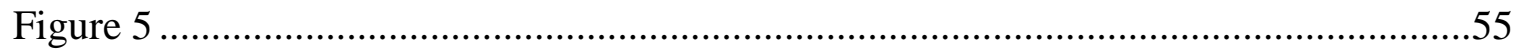

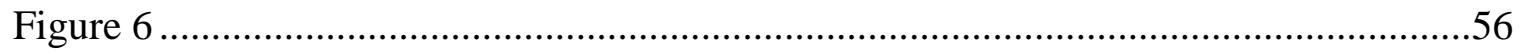

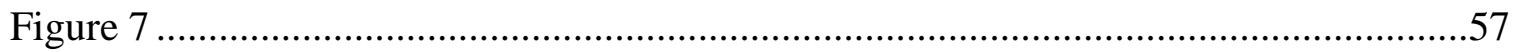

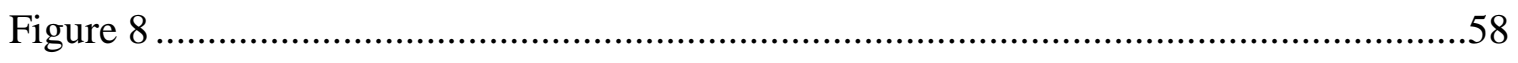

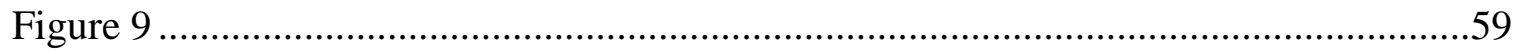

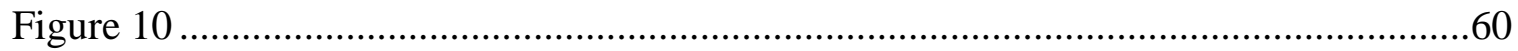

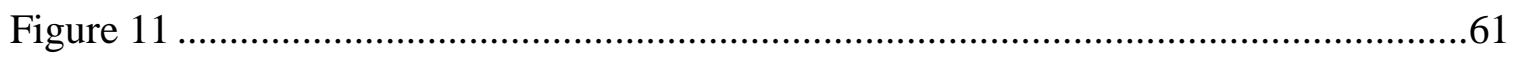

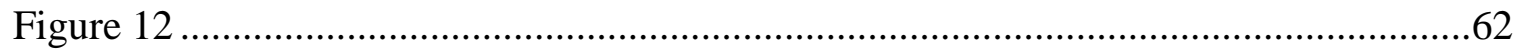

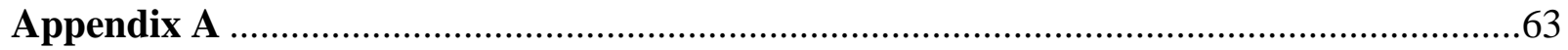

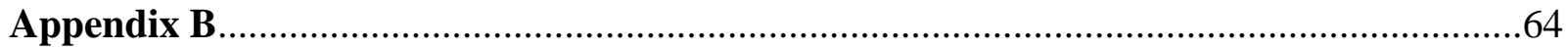




\section{$\underline{\text { Acknowledgements }}$}

The completion of this thesis would certainly not have been possible without the contributions and support of many individuals. I wish to extend my heartfelt "thanks" to each and every one of you. Dr. Vicki Blazer, thank you for giving me the opportunity to participate in your research at USGS and for the opportunity to go back to school. You are an inspiring role model, an unrivaled scientist, and an excellent mentor who has opened my world to the challenges and insights of science. Thank you to Dr. Patricia Mazik for your guidance, reassurance, and positivity along the way. Although "nothing simple is ever easy," you made every aspect of my graduate program much easier with your assistance and dedication, and for that I am grateful. Thank you to the other members of my committee, Amy Welsh and AB Billings, for challenging me, for fostering my interest in genetics and statistics, and for offering

your time and support. Special thanks to Dr. Sadie Bergeron, who graciously allowed me to use her microscope for several months free of charge. Thank you to the Great Lakes Restoration Initiative for the funding to complete this project. Thank you to Kathy Springer, Darlene Bowling, and Pam Whittington for preparing the histology slides and for the many memorable conversations. Thank you to Adam Sperry for being my "guardian angel" in the lab and a genuine friend. Finally, thank you to my parents for a lifetime of encouragement and support. 


\section{Chapter 1}

\section{Background Information}

In 2010 the Great Lakes Restoration Initiative (GLRI) was developed to identify the major threats to the Great Lakes ecosystem and to accelerate progress toward achieving longterm environmental restoration goals. The Great Lakes are a vital resource to many industrial, agricultural, and commercial industries, but have suffered decades of pollution. Chemicals used by these industries continue to make their way into surface waters through runoff, leaking septicconveyance systems, regulated and unregulated discharges, and combined sewer overflows, among other sources (Baldwin et al. 2016). Detected concentrations of chemical pollutants indicate a high potential for adverse impacts on aquatic organisms and have raised concern about the potential risk to the more than 40 million people who rely on the Great Lakes for drinking water. The GLRI Action Plan was established to target five Focus Areas addressing environmental problems and associated human health issues: remediation of toxic Areas of Concern (AOCs), control of invasive species, reduction of nutrient runoff, restoration of native species habitat, and incorporation of a science-based adaptive management framework. Fortythree sections of the Great Lakes Region are currently designated AOCs, defined as specific geographic areas in which environmental degradation impaired the area's ability to support aquatic life ("Great Lakes Water Quality Agreement" 2012). An AOC is eligible for delisting when all Beneficial Use Impairments (BUIs) are removed. Examples of beneficial use impairments include, but are not limited to, (1) restrictions on drinking water consumption, (2) restrictions on fish and wildlife consumption, and (3) fish tumors or other deformities. Legacy contaminants such as heavy metals, polycyclic aromatic biphenyls (PBCs), and polycyclic aromatic hydrocarbons (PAHs) were historically identified as potential causes for many of the 
BUIs, although more recently, a number of efforts have been undertaken to characterize and assess the risk of chemicals of emerging concern (CECs), defined as any chemicals or compounds that are newly recognized, not routinely monitored, but have the potential to cause adverse ecological and/or human health effects. Common categories of CECs are current use pesticides, personal care products, pharmaceuticals, detergents, plasticizers, brominated flame retardants, and synthetic hormones. Previous studies have documented the detection of these chemicals in the Great Lakes in recent years (Lee et al. 2012; Lee et al. 2015). Compared to the more highly regulated contaminants, effects of CECs are not well understood. Some chemicals have been shown to cause serious effects such as the feminization of male fish or immunomodulation in laboratory (Kang et al. 2002; Milston et al. 2003; Watanuki et al. 2003; Yin et al. 2007; Yang et al. 2015) and field settings (Blazer et al. 2007; Thomas et al. 2017). Although effects of contaminants on the teleost reproductive system have been most commonly documented, other important systems can be affected by exposure to CECs and legacy contaminants. One such system is the thyroid axis, which plays a crucial role in the coordination of physiological processes and maintenance of homeostasis in all vertebrates, most notably in the control of development, growth, metabolism, and reproduction (Power et al. 2001; Blanton and Specker 2007).

In 1998, the United States EPA recommended consideration of contaminant effects on the teleost thyroid axis when screening for effects of endocrine disrupting compounds (EDCs) because disruption of the axis constitutes a threat to fish health on the population level (U.S. EPA 1998). Since then, a great deal of research showing relationships between EDCs and various thyroid parameters in fish has emerged in both laboratory and field settings (Brown et al. 2004). However, much of the research focuses on the use of model organisms such as fathead 
minnow (Pimephales promelas), zebrafish (Danio rerio), rainbow trout (Oncorhynchus mykiss), and medaka (Oryzias latipes). While information on these species has greatly contributed to our understanding of mechanisms, similar information for wild fish species is still lacking. For this reason, two wild-caught, freshwater species were chosen for this study.

The two wild fish species targeted for analyses were based on their representation of either a benthic or pelagic community. The benthic species is an opportunistic benthivore that commonly burrows into soft sediment: brown bullhead (Ameiurus nebulosus). The pelagic species is a top carnivore of commercial and recreational importance: smallmouth bass (Micropterus dolomieu). It has been demonstrated that smallmouth bass (SMB) is a reliable sentinel species for monitoring effects of estrogenic contaminants in the Great Lakes (Blazer et al. 2014; Blazer et al. 2018) and elsewhere, responding by induction of vitellogenin and testicular oocytes (intersex) in males (Blazer et al. 2007; Blazer et al. 2012; Kadlec et al. 2017). Brown bullhead (BBH) have also been used in the Great Lakes watershed as an indicator species, particularly in the evaluation of the presence of liver and skin tumors and other adverse effects (Baumann et al. 1996; Blazer et al. 2009a,b; Rafferty et al. 2006; Smith et al. 1989). It is currently unknown if these species have the potential to be valuable models for thyroid disruption research.

Biomonitoring for thyroid disruptors in the aquatic environment traditionally employs histological biomarkers and thyroid hormone analysis. These biological endpoints are important because they often relate to known impairments, although they are not specific to the contaminants and can be influenced by factors including age, gender, diet, and season (Rolland 2000). Gene expression analysis has recently been shown to be a valuable biomarker for monitoring thyroid disrupting chemicals (Scholz and Mayer 2008; Garcia-Reyero et al. 2009; Fu 
et al. 2017). However, no prior study has examined gene expression in conjunction with the traditional endpoints.

\section{Teleost Thyroid}

Among endocrine organs, the thyroid is the most highly conserved throughout vertebrates (Norris and Lopez 2011) and is often a key target of xenobiotics (Schnitlzer et al. 2008). Thyroid hormones (THs) produced by the gland are essential for early development in teleost fishes, including larval-juvenile transitions in marine flatfishes and eels, the regulation of rates of morphogenesis and metamorphosis in goldfish, conger eels, and flounder, and smoltification in salmonids (Dickhoff et al. 1982; Jobling; Miwa et al. 1988; Power et al. 2001; Yamano et al. 1991). It has been suggested that photoperiod, temperature, and diet regulate seasonal thyroid cycles, and that seasonal changes of THs may be associated with the reproduction in teleost fishes (Comeau et al. 2000). This indicates a potential TH function in the control of both sexual differentiation and reproductive development (Cyr and Eales 1996). The latter is supported by a report on the masculinization of sticklebacks by perchlorate, an inhibitor of TH synthesis (Bernhardt et al., 2006). Furthermore, THs are also involved in the regulation of the immune system, as indicated by the suppression of immune function by hyperthyroidism (Yada and Nakanishi 2002).

\section{Hypothalamus-Pituitary-Thyroid Axis}

The physiological functions of the thyroid gland in fish, like those of most vertebrates, are regulated by the hypothalamus-pituitary-thyroid (HPT) axis. Thyroid hormones are produced upon activation of the HPT axis, which maintains plasma hormones at appropriate levels. Following environmental stimuli and/or internal feedback mechanisms acting on the hypothalamus, the anterior pituitary synthesizes and releases thyroid-stimulating hormone (TSH) 
which in turn triggers the biosynthesis of all thyroxine (T4) and a small percentage of 3,5,3'triiodothyronine (T3). Thyroxine is considered the inactive precursor, or prohormone, of the THs, whereas T3 is the metabolically active form acting on tissues (Higgs et al. 1982). Triiodothyronine generally increases basal metabolic speed and greatly affects energy consumption (Eales 2006; Yen 2001). An important feature of the HPT axis is the negative feedback action of T4 on TSH secretion, thereby regulating the synthesis and release of T4. The cellular components of the HPT axis in teleost fish are similar to those of mammals (Blanton and Specker 2008), but unlike in higher vertebrates, thyroid tissue in fish is organized into diffuse follicles rather than an encapsulated gland. These circular follicles consist of a single layer of epithelial cells enclosing a colloid-filled lumen, bound together by connective tissue in the pharyngeal region of the fish. T4 is stored within the lumen of the follicle in the form of colloid. The hormone is held within the colloid by being securely bound to thyroglobulin (Brown et al. 2004), a large iodinated protein. It is thought that T4 enters the blood by a sequence of intricate changes within the stimulated cell. First the apical membrane of epithelial cells engulfs colloid by endocytosis. Cytoplasmic colloid droplets fuse with lysosomes to form phagolysosomes. Within these phagolysosomes, lysis and degradation of thyroglobulin occurs to release T4. The THs are subsequently released into circulation by simple diffusion and are transported in the blood bound to transport proteins. T4 is a chosen endpoint because it is centrally controlled and can be reliably monitored from the plasma total T4 levels and from follicle histological appearance (Brown et al. 2004).

Most of T3 is found in the blood and is not directly secreted by the thyroid follicles, but rather results from the action of deiodination enzymes (DIOs, DIO1 and DIO2) on T4. Deiodination mainly occurs in the liver, but can occur in other peripheral tissues such as the 
brain and the kidney. DIOs are responsible for coordinating the tissue-specific metabolism of THs. The peripherally controlled conversion of T4 to T3, and hence the T3 availability to target cell receptors, cannot be monitored reliably from plasma T3 level alone, but the potential production of $\mathrm{T} 3$ can be assessed in vitro from the DIO activities in target tissues such as the liver. DIOs are sensitive to the ratio of T4 to T3 concentrations in the blood. In general, high levels of THs, i.e. hyperthyroidism, cause decreases in DIO2 gene expression and enzymatic activity. Low levels of THs, i.e. hypothyroidism, induce the opposite effect. Deiodination levels, along with plasma T3 levels, has been proposed as a valuable biomarker of interference of the thyroid system in fish (Eales et al. 1999). In addition, the ratio of T3 to T4 (T3/T4) can serve as a simple measure of deiodinase activity and conversion efficiency.

\section{Thyroid Hormone Actions in Fish}

The primary action of THs on target tissues is to regulate synthesis of specific proteins. This mainly involves bioactive T3 binding to nuclear receptors, members of the nuclear receptor superfamily (along with glucocorticoid, estrogen, vitamin D, and retinoic acid receptors) known for mediating the stress response. The nuclear receptors are encoded by two distinct genes (TR $\alpha$ and TR $\beta$ ) which are also found in higher vertebrates (Bassett et al. 2003). The receptors bind in pairs to thyroid response elements, each consisting of a specific five base pair region of DNA. Ultimately, binding of $\mathrm{T} 3$ to its base on nuclear receptors regulates the expression of specific genes by activating or suppressing transcription rates. The resulting RNA is then edited to mRNA and translated on ribosomes to form proteins. It has been shown that THs are capable of modulating TH function at the receptor level (Yamano 2005). Therefore, TH receptors may provide information on potential modes of action following contaminant exposure. 


\section{Mechanisms of Interference}

The complexity of the thyroid system allows EDCs to impact at many points. Overall, chemicals can disrupt thyroid function by altering circulating $\mathrm{TH}$ levels, by decreasing $\mathrm{TH}$ secretion, by increasing TH metabolism, or by interfering with TH action. Organochlorines, such as the DDT and Endrin, can interfere directly with hormone synthesis in the thyroid gland (Grant and Mehrle 1970; Wade et al. 2002). Other chemicals like bisphenol A (BPA) and polychlorinated biphenyl (PCB) congeners are structurally similar to THs and can competitively bind to TH binding proteins like transthyretin in the blood (Wade et al. 2002; Ishihara et al. 2003; Iwamuro et al. 2003; Boas et al. 2006). Estrogenic compounds have also been observed to interfere with TR binding to T4, leading to decreased circulating levels of T4 (Morgado et al. 2009). Heavy metals such as mercury, cadmium, and lead can also act on enzymes which activate or inactivate thyroid hormones (Paier et al. 1993; Watanabe et al. 1999). Finally, pollutants like PCBs can disrupt TH receptors and accessory proteins which directly control the gene expression through TH responsive elements (Ishihara et al. 2003; Blanton and Specker 2007). Besides the direct effects on the thyroid, indirect effects via the hypothalamus and anterior pituitary gland are also possible (Ishihara et al. 2003; Zoeller et al. 2007).

\section{Thyroid Histological Biomarkers}

Thyroid dysfunction in fish has multiple classical manifestations at the cellular level and can be assessed histologically. Associations between certain types of microscopic thyroid lesions and chemical pollutants have been observed in laboratory studies (Ram and Sathyanesan 1987; Liu et al. 2006; Dong et al. 2014) as well as field studies (Bernet et al. 1999; Gilroy et al. 2012). Histopathological endpoints include follicular vacuolation, epithelial cell height (hypertrophy), and hyperplasia. Thyroid epithelial cell hypertrophy is the increase in size of the tissue due to 
enlargement of the epithelial cells. It is the most commonly used and most sensitive histopathological endpoint in evaluating thyroid activity because it is considered roughly proportional to the degree of response to stimuli (Moccia et al. 1981). Moreover, epithelial cells are responsible for synthesizing and secreting THs, thus an increase in cell size (hypertrophy) are indicative of an increase in functional demand. Hyperplasia is distinguished from hypertrophy in that cells remain approximately the same in size but increase in number. For example, follicular cell hyperplasia is diagnosed when there is follicular cell crowding or stratification (multiple layers of cells). Severity of colloid depletion is another routinely employed biomarker to investigate thyroid function. According to Moccia et al. (1981), highly vacuolated colloid or the absence of luminal colloid is considered a pathological condition.

\section{Thyroid Disruption Field Studies}

Most of the contaminants implicated as thyroid disruptors in previous studies are legacy chemicals, with field studies reporting alterations in thyroid gland morphology and hormone levels in fish as early as the 1970s. The occurrence of thyroid hyperplasia (an increase in the number of cells) in Great Lakes salmon was first reviewed by Leatherland and Sonstegard (1976). Stocked Pacific salmon experienced an epizootic outbreak of enlarged thyroid glands (goiters). By 1979, goiters were reported in salmon from Lakes Erie (89\%), Ontario (35\%), and Michigan (16\%) (Leatherland and Sonstegard 1984). In addition to the high frequency of goiter reported in coho from Lake Erie, the fish also displayed poorly developed secondary sexual characteristics and poor reproductive success. Embryo mortality in Lake Erie coho salmon (75\%) was very high when compared to mortality in coho from Lakes Ontario (20\%) and Michigan (20\%). High plasma TH levels were also reported. Leatherland and Sonstegard (1984) suggested that the combined signs were indicative of endocrine disruption. The lesions were similar 
histologically to those described in Great Lakes herring gulls (Moccia et al. 1986). This similarity not only supports the hypothesis of a common environmental cause, but also suggests that thyroid inhibitory substances can pass through the food chain (Leatherland 1998). A followup study by the same author showed that polychlorinated hydrocarbons including various PCB congeners were mainly responsible for these thyroid perturbations in Great Lakes fish and predatory birds (Leatherland 1998).

A more recent example involved a study of plasma TH concentrations in shiner surfperch (Cymatogaster aggregata) and staghorn sculpin (Leptocottus armatus) in San Francisco Bay. The findings showed significant reductions in plasma T4 and perturbations in T3/T4 ratios that were strongly correlated with hepatic PCB concentrations (Brar et al. 2010). The same study also identified several relationships between chlorinated pesticides and altered thyroid parameters in both species. In surfperch, pesticide concentrations were positively correlated with T3 and T3/T4 ratios and showed an inverse (yet non-significant) trend with T4 levels. A similar pattern of response was evident for sculpin, although this species exhibited additional site-associated reductions in T4. It was suggested that sculpin, a benthic species, may be more sensitive to environmental effects as compared with surfperch.

In a field study at PCB-contaminated Wheatley Harbour (Lake Erie AOC), perturbations in the thyroid status were found in brown bullhead and goldfish, including lower plasma concentrations of thyroid hormones and/or elevated liver deiodinase activity (Gilroy et al. 2012). Wheatley Harbor goldfish also exhibited increased epithelial cell heights (hypertrophy) and partially depleted colloid area and volume. Depleted colloid indicates disruption of the balance between TH synthesis and use (Theodorakis et al. 2006). The decrease in colloid was consistent with an observed depletion of circulating T4 concentrations. The increase in TECA relative to 
colloid area and the corresponding increase in TECH was thought to be a compensatory effort to maintain concentrations of circulating T4.

Schnitzler et al. (2012) investigated thyroid function in wild sea bass collected near several estuaries in Europe and found that, particularly in fish exposed to high PCB concentrations, changes in thyroid hormone metabolism led to an increased conversion of T4 to T3 and reduced thyroid hormone excretion. Authors hypothesized that, because of structural similarities, PCBs were able to displace THs from serum binding proteins, causing a decrease in serum levels. This may explain the correlation found between T3/T4 ratio and PCBs in fish from the Great Lakes Wheatley Harbor study.

Song et al. (2012) found elevated serum levels of TSH and depressed levels of T4 in crucian carp (Carasssius auratus) from a site contaminated with polybrominated diphenyl ethers (PBDEs). This site was on a river close to an electronic waste site in China. The average muscle PBDE concentration in affected fish was $236 \mathrm{ng} / \mathrm{g}$ wet weight.

Not all studies found depressed T4 levels. In the case of Zhou et al. (2000), authors found significantly elevated T4 levels and a trend of reduced T3 levels in mummichog (Fundulus heteroclitus) from site in New Jersey contaminated by heavy metals, organochlorines, and PAHs. The fish from the contaminated habitat had larger thyroid follicles and taller epithelial cell heights. These findings suggest that pollutants may have affected conversion of T4 to T3.

Iwanowicz et al. (2012) observed thyroid hormone perturbations consistent with PCBinduced thyroid disruption in brown bullhead and largemouth bass. Results showed decreased TH concentrations in both brown bullhead and largemouth bass from the Astabula River AOC when compared to a reference site (Conneaut Creek), with a strong negative correlation of plasma T4 and T3 levels with PCB body burden. Seasonal changes in plasma THs were also 
observed in both species, with low levels occurring in summer and higher levels occurring in spring. THs were not different in summer when levels were low, whereas spring levels were lower in the Ashtabula River, suggesting that thyroid hormone disruption may only take place when the thyroid is stimulated.

\section{Objectives of the Current Study}

This thesis builds upon the GLRI biomarker framework through investigation of the teleost thyroid system in selected sites within Great Lakes AOCs. To date, SMB have not been used in thyroid disruption studies, while very little information exists on BBH thyroid status. Specifically, this thesis aims to evaluate associations between commonly studied thyroid endpoints, thyroid hormone (TH) levels and thyroid gland histology, in conjunction with a novel endpoint: gene expression. Gene expression is a feature of this study that has not previously been assessed with thyroid histology and TH levels. Chapter 1 of this thesis consists of (1) an

overview of the teleost thyroid system and reasoning for the chosen endpoints and (2) a literature review of previous thyroid disruption studies, some of which were conducted in Great Lakes AOCs. Chapter 2 focuses on both the analysis of the chosen endpoints and the evaluation of these species for use as bioindicators of thyroid disruption.

Objectives for this thesis are as follows:

1. Determine associations between thyroid-related endocrine disruption endpoints

a. Investigate histological features of thyroid follicles and to determine whether morphological changes are associated with the functional activity of the follicles

b. Investigate whether hepatic gene expression profiles can help explain histologic or hormonal responses.

2. Evaluate the potential of $\mathrm{SMB}$ and $\mathrm{BBH}$ as bioindicator species of thyroid disruption 


\section{Literature Cited}

Baldwin, A.K., S.R. Corsi, L.A. De Cicco, M.A. Lutz, D.J. Sullivan, K.D. Richards. (2016). "Organic contaminants in Great Lakes tributaries: prevalence and potential aquatic toxicity." Science of the Total Environment 554-555:42-52.

Bassett, J.H., C.B. Harvey, G.R. Williams. (2003). "Mechanisms of thyroid hormone receptorspecific nuclear and extra nuclear actions." Molecular and Cellular Endocrinology 213(1): $1-11$.

Baumann, P.C., I.R. Smith, C.D. Metcalfe. (1996). "Linkages between chemical contaminants and tumors in benthic Great Lakes fish.” Journal of Great Lakes Research 22:131-152.

Bernet, D., H. Schmidt, W. Meier, P. Burkhardt-Holm, T. Wahli. (1999). "Histopathology in fish: proposal for a protocol to assess aquatic pollution." Journal of Fish Diseases 22, 25 34 .

Bernhardt, R. R. and von Hippel, F.A. (2008). "Chronic perchlorate exposure impairs stickleback reproductive behaviour and swimming performance.” Behaviour 145(4-5), 537-559.

Blanton, M.L. and Specker, J.L. (2008). "The hypothalamic-pituitary-thyroid (HPT) axis in fish and its role in fish development and reproduction." Critical Reviews in Toxicology 37(12): 97-115.

Blazer, V.S. et al. (2007). "Intersex (testicular oocytes) in smallmouth bass from the Potomac River and selected nearby drainages." Journal of Aquatic Animal Health 19(4):242-53.

Blazer, V.S. et al. (2009a). "Assessment of the "tumors or other deformities" beneficial use impairment in brown bullhead: I. Orocutaneous tumors." Journal of Great Lakes Research 35:517-526.

Blazer, V.S. et al. (2009b). "Assessment of the 'tumors and other deformities' beneficial use impairment in brown bullhead: II. Liver tumors." Journal of Great Lakes Research 35:527-537.

Blazer, V.S. et al. (2012). "Reproductive endocrine disruption in smallmouth bass (Micropterus dolomieu) in the Potomac River basin: spatial and temporal comparisons of biological effects." Environmental Monitoring and Assessment 184(7): 4309-4334.

Blazer, V. S. et al. (2014). "Monitoring of wild fish health at selected sites in the Great Lakes basin - methods and preliminary results." U.S. Geological Survey Open-File Report, 2014-1027, 31 https://doi.org/10.3133/ofr20141027.

Blazer, V.S. et al. (2018). "Indicators of exposure to estrogenic compounds at Great Lakes areas of concern: species and site comparisons." Environmental Monitoring and Assessment 190(10):577 doi: 10.1007/s10661-018-6943-5.

Boas, M., U. Feldt-Rasmussen, N.E. Skakkebaek, K.M. Main. (2006). "Environmental chemicals and thyroid function." European Journal of Endocrinology 154(5):599-611. 
Brar, N. K., C. Waggoner, J.A. Reyes, R. Fairey, K.M. Kelley. (2010). "Evidence for thyroid endocrine disruption in wild fish in San Francisco Bay, California, USA. Relationships to contaminant exposures." Aquatic Toxicology 96(3): 203-215.

Brown, S.B. B.A. Adams, D.G. Cyr, J.G. Eales. (2004). "Contaminant effects on the teleost fish thyroid." Environmental Toxicology and Chemistry 23(7):1680-1701.

Cyr, D.G. and Eales, J.G. (1996). "Interrelationships between thyroidal and reproductive endocrine systems in fish." Reviews in Fish Biology and Fisheries 6:165-200.

Dickhoff, W.W., L.C. Folmar, J.L. Mighell, C.V.W. Mahnken. (1982). "Plasma thyroid hormones during smoltification of yearling and underyearling coho salmon and yearling chinook salmon and steelhead trout." Aquaculture 28(1-2): 39-48.

Dong, Y., H. Tian, W. Wang, X. Zhang, J. Liu, S. Ru.(2014). "Disruption of the thyroid system by the thyroid-disrutping compound Aroclor 1254 in juvenile Japanese flounder (Paralichthys olivaceus)." PLOS ONE 9(8):e104196.

Eales, J.G., S.B. Brown, D.G. Cyr, B.A. Adams, K.R. Finnson. (1999). "Deiodination as an index of chemical disruption of thyroid hormone homeostasis and thyroidal status in fish." Environmental Toxicology and Risk Assessment: Standardization of Biomarker for Endocrine Disruption and Environmental Assessment 8:136-153.

Eales, J.G. (2006). "Modes of action and physiological effects of thyroid hormones in fish." Fish Endocrinology 2:767-808.

Fu, D., A. Bridle, M. Leef, M.M. Gagnon, K.L. Hassell, B.F. Nowak. (2017). "Using a multibiomarker approach to assess the effects of pollution on sand flathead (Platycephalus bassensis) from Port Phillip Bay, Victoria, Australia." Marine Pollution Bulletin 119(1): 211-219.

Garcia-Reyero, N., I.R. Adelman, D. Martinovic, L. Liu, N.D. Denslow. (2009). "Site-specific impacts on gene expression and behavior in fathead minnows (Pimephales promelas) exposed in situ to streams adjacent to sewage treatment plants." 10(11):S11.

Gilroy, E.A., M.E. McMaster, J.L. Parrott, L.M. Hewitt, B.J. Park, S.B. Brown, J.P. Sherry. (2012). "Assessment of the health status of wild fish from the Wheatley Harbour Area of Concern, Ontario, Canada.” Environmental Toxicology 31(12): 2798-2811.

Grant, B.F. and P.M. Mehrle. (1970). "Chronic endrin poisoning in goldfish, Carassius auratus." Journal of the Fisheries Research Board of Canada 27:2225-2232.

Higgs, D.A., H.M. Fagerlund, J.G. Eales, J.R. McBride. (1982). “Application of thyroid and steroid hormones as anabolic agents in fish culture." Comparative Biochemistry and Physiology Part B: Comparative Biochemistry 73(1): 143-176.

IJC. (2009). Great Lakes Water Quality Agreement Priorities 2007-09 Series. Windsor, Ontario, Canada. 
Ishihara, A., S. Sawatsubashi, K. Yamauchi. (2003). "Endocrine disrupting chemicals: interference of thyroid hormone binding to transthyretins and to thyroid hormone receptors." Molecular and Cellular Endocrinology 199(1-2):105-117.

Iwamuro, S., M. Sakakibara, M. Terao, A. Ozawa, C. Kurobe, T. Shigeura, M. Kato, S. Kikuyama. (2003). "Teratogenic and anti-metamorphic effects of bisphenol A on embryonic and larval Xenopus laevis. General and Comparative Endocrinology 133:189198.

Iwanowicz, L.R., V.S. Blazer, N.P. Hitt, S.D. McCormick, D.S. DeVault, C.A. Ottinger. (2012). "Histologic, immunologic and endocrine biomarkers indicate contaminant effects in fishes of the Ashtabula River.” Ecotoxicology 21(1):165-82.

Jobling, M. (1995). Environmental Biology of Fishes. Chapman and Hall, Boundary Row, London.

Kadlec, S.M., R.D. Johnson, D.R. Mount, J.H. Olker, B.D. Borkholder, P.K. Schoff. (2017). "Testicular oocytes in smallmouth bass in northeastern Minnesota in relation to varying levels of human activity." Environmental Toxicology and Chemistry 36:3424-3435.

Kang, I.J, H. Yokota, Y. Oshima, Y. Tsuruda, T. Oe, N. Imada, H. Tadokoro, T. Honjo. (2002). "Effects of bisphenol a on the reproduction of Japanese medaka (Oryzias latipes). Environmental Toxicology and Chemistry 21(11):2394-400.

Leatherland, J.F. and Sonstegard, R.A. (1976). "The epizootiology and pathogenesis of thyroid hyperplasia in coho salmon (Oncorhynchus kisutch) in Lake Ontario." Cancer Research 36:4467-4475.

Leatherland, J.F. and Sonstegard, R.A. (1984). "Pathobiological responses of feral teleosts to environmental stressors: interlake studies of the physiology of Great Lakes salmon." p. 115-149 In: V.W. Cairns, P.V. Hodson, J.O. Nriagru (eds.). Contaminant Effect on Fisheries. John Wiley and Sons, New York.

Leatherland, J.F. (1998). "Changes in thyroid hormone economy following consumption of environmentally contaminated Great Lakes fish.” Toxicology and Industrial Health 14:41-57.

Lee, K.E., S.K. Langer, M.A. Menheer, W.T. Foreman, E.T. Furlong, S.G. Smith. (2012). "Chemicals of emerging concern in water and bottom sediment in Great Lakes areas of concern, 2010 to 2011 - Collection methods, analyses methods, quality assurance, and data." U.S. Geological Survey Data Series 723, 26 p., http://pubs.usgs.gov/ds/723.

Lee, K.E., S.K. Langer, M.A. Menheer, D. Gefell. (2015). "Chemicals of emerging concern in water and bottom sediment in Great Lakes Basin, 2012 - Collection methods, analytical, methods, quality assurance, and study data." U.S. Geological Survey Data Series 910, 14 p., http://dx.doi.org/10.3133/ ds910. 
Liu, F.J., J.S. Wang, C.W. Theodorakis. (2006). "Thyrotoxicity of sodium arsenate, sodium perchlorate, and their mixture in zebrafish Danio rerio." Environmental Science Technology 40:3429-3436.

Milston, R.H., M.S. Fitzpatrick, A.T. Vella, S. Clements, D. Gundersen, G. Feist, T.L. Crippen, J. Leong, and C.B. Schreck. (2003). "Short-term exposure of Chinook salmon (Oncoryhnchus tshawytscha) to o,p-DDE or DMSO during early life-history stages causes long-term humoral immunosuppression." Environmental Health Perspectives 111:1601-1607.

Miwa, S., M. Tagawa, Y. Inui, T. Hirano. (1988). "Thyroxine surge in metamorphosing flounder larvae." General and Compartive Endocrinology 70:158- 163.

Moccia, R.D., J.F. Leatherland, R.A. Sonstegard. (1981). "Quantitative interlake comparison of thyroid pathology in Great Lakes coho (Oncorynchus kisutch) and chinook (Oncorhynchus tschawytscha) salmon." Cancer Research 41:2200-2210.

Moccia, R.D., G.A. Fox, A. Britton. (1986). “A quantitative assessment of thyroid histopathology of herring gulls (Larus argentatus) from the Great Lakes and a hypothesis on the causal role of environmental contaminants." Journal of Wildlife Disease 22(1):6070.

Morgado, I., M.A. Campinho, R. Costa, R. Jacinto, D.M. Power. (2009). "Disruption of the thyroid system by diethylstilbestrol and ioxynil in the sea bream (Sparus auratus)." Aquatic Toxicology 92:271-280.

Norris, D.O. and Lopez, K.H. (2011). Hormones and Reproduction of Vertebrates, Volume 1: Fishes. Academic Press.

Nugegoda, D. and Kibria, G. (2017). "Effects of environmental chemicals on fish thyroid function: implications for fisheries and aquaculture in Australia." General and Comparative Endocrinology 244(1):40-53.

Paier, B., K. Hagmuller, M.I. Noli, M.G. Pondal, C. Stiegler, A.A. Zaninovich. (1993). "Changes induced by cadmium administration on thyroxine deiodination and sulfhydryl groups in rat liver." Journal of Endocrinology 138:219-224.

Power, D.M., L. Llewellyn, M. Faustino, M.A. Nowell, B.T. Bjornsson, I.E. Einarsdottir, A.V.M. Canario, G.E. Sweeney. (2001). "Thyroid hormones in growth and development of fish." Comparative Biochemistry and Physiology Part C: Toxicology and Pharmacology 130:447-459.

Rafferty, S.D. and Grazio, J.L. (2006) "Field manual for assessing internal and external anomalies in brown bullhead (Ameiurus nebulosus)" accessed October 9, 2018, at http://seagrant.psu.edu/publications/technical docs/bullheadfieldmanual.pdf.

Ram, R.N. and Sathyanesan, A.G. (1987). "Histopathological changes in liver and thyroid of the teleost fish, Channa punctatus (Bloch), in response to ammonium sulfate fertilizer treatment." Ecotoxicology and Environmental Safety 13(2):185-190. 
Rolland, R. (2000). "A review of chemically-induced alterations in thyroid and vitamin: a status from field studies of wildlife and fish.” Journal of Wildlife Disease 36:615-635.

Scholz, S. and Mayer, I. (2008). "Molecular biomarkers of endocrine disruption in model fish." Molecular and Cellular Endocrinology 293(1-2):57.

Schnitzler, J. G., E. Koutrakis, U. Siebert, J.P. Thome, K. Das. (2008). "Effects of persistent organic pollutants on the thyroid function of the European sea bass (Dicentrarchus labrax) from the Aegean sea, is it an endocrine disruption?" Marine Pollution Bulletin 56(10):1755-1764.

Simmons, D.B., M.E. McMaster, E.J. Reiner, L.M. Hewitt, J.L. Parrott, B.J. Park, S.B. Brown, J.P. Sherry. (2014). "Wild fish from the Bay of Quinte Area of Concern contain elevated tissue concentrations of PCBs and exhibit evidence of endocrine-related health effects." Environment International 66:124-137.

Smith, I.R., H.W. Ferguson, M.A. Hayes. (1989). "Histopathology and prevalence of epidermal papillomas epidemic in brown bullhead, Ictalurus nebulosus (Lesueur) and white sucker, Catostomus commersoni (Lacepede), populations from Ontario, Canada." Journal of Fish Diseases 12:373-388.

Song, Y., N. Wu, H. Tao, Y. Tan, M. Gao, J. Han, H. Shen, K. Liu, J. Lou. (2012). “Thyroid endocrine dysregulation and erythrocyte DNA damage associated with PBDE exposure in juvenile crucian carp collected from an e-waste dismantlging site in Zhejiang province, China." Environmental Toxicology and Chemistry 31(9):2047-2051.

Theodorakis, C.W., J. Rinchard, J.A. Carr, J.W. Park, L. McDaniel, F. Liu, M. Wages. (2006). "Thyroid endocrine disruption in stonerollers and cricket frogs from perchloratecontaminated streams in east-central Texas." Ecotoxicology 15:31-50.

Thomas, L.M., Z.G. Jorgenson, M.E. Brigham, S.J. Choy, J.N. Moore, J.A. Banda, D.J. Gefell, T.A. Minarik, H.L. Schoenfuss. (2017). "Contaminants of emerging concern in tributaries to the Laurentian Great Lakes: II biological consequences of exposure.” PLOS ONE 12(9):e0184725.

U.S. EPA. (1998). Endocrine Disruptor Screening and Testing Advisory Committee (EDSTAC) Report. Washington, DC:U.S. Environmental Protection Agency, Office of Prevention, Pesticides and Toxic Substances. https://www.epa.gov/endocrine-disruption/endocrinedisruptor-screening-and-testing-advisory-committee-edstac-final

Wade, M.G., S. Parent, K.W. Finnson, W. Foster, E. Younglai, A. McMahon, D.G. Cyr, C. Hughes. (2002). "Thyroid toxicity due to subchronic exposure to a complex mixture of 16 organochlorines, lead, and cadmium.” Toxicology Sciences 67:207-218.

Watanabe, C., K. Yoshida, Y. Kasanuma, Y. Kun, H. Satoh. (1999). "In utero methylmercury exposure differentially affects the activities of selenoenzymes in the fetal mouse brain." Environmental Research 80:208-214. 
Watanuki, H., Y. Gushiken, M. Sakai. (2003). "In vitro modulation of common carp (Cyprinus carpio) phagocytic cells by Di-n-butyl phthalate and Di2-ethylhexyl phthalate." Aquatic Toxicology 63:119- 126.

Yada, T. and Nakanishi, T. (2002). "Interaction between endocrine and immune systems in fish." International Review of Cytology 220:35-92.

Yamano, K., M. Tagawa, E. Grace de Jesus, T. Hirano, S. Miwa, T. Inui. (1991). "Changes in whole body concentrations of thyroid hormones and cortisol in metamorphosing conger eel." Journal of Comparative Physiology B 161:371-375.

Yamano, K. (2005). "The role of thyroid hormone in fish development with reference to aquaculture." Japan Agricultural Research Quarterly 39(3):161-168.

Yang, M., W. Qiu, B. Chen, J. Chen, S. Liu, M. Wu, K.J. Wang. (2015). "The in vitro immune modulatory effect of bisphenol A on fish macrophages via estrogen receptor $\alpha$ and nuclear factor-kB signaling." Environmental Science and Technology 49:1888-1895.

Yen, P.M. (2001). "Physiological and molecular basis of thyroid hormone action." Physiological Reviews 81:1097-1142.

Yin, D.Q., S.Q. Hu, Y. Gu, L. Wei, S.S. Liu, A.Q. Zhang. (2007). "Immunotoxicity of bisphenol A to Carassius auratus lymphocytes and macrophages following in vitro exposure." Journal of Environmental Science (China). 19:232-237.

Zhou, T., H.B. John-Alder, J.S. Weis, P. Weis. (2000). "Endocrine disruption: thyroid dysfunction in mummichogs (Fundulus heteroclitus) from a polluted habitat." Marine Environmental Research 50:393:397.

Zoeller, R.T. (2007). "Environmental chemicals impacting the thyroid: targets and consequences." Thyroid 17(9):811-7. 
Chapter 2: An interspecies investigation of thyroid plasma hormone levels, histology, and gene expression to assess potential thyroid-related endocrine disruption

\begin{abstract}
A high prevalence of endocrine disrupting chemicals (EDCs) in Great Lakes Areas of Concern (AOCs) has raised concerns as to the health and fitness of fish and wildlife. It is not well understood to what extent existing contaminants, many with continuing inflows into the environment, may impact fish populations. This study provides an initial characterization of thyroid endocrine-related effects in two indigenous fish species sampled from Great Lakes
\end{abstract} AOCs. Biomonitoring was conducted on a pelagic, top predator species, smallmouth bass (Micropterus dolomieu) and benthic, omnivorous brown bullhead (Ameiurus nebulosus) at 7 sites in spring and fall of 2012. Thyroidal endpoints, such as plasma hormone levels (plasma thyroid stimulating hormone- TSH, thyroxine - T4, and triiodothyronine- $-\mathrm{T} 3$ ), thyroid histology (thyroid epithelial cell height and colloid depletion), and expression levels of thyroid-related genes (Thyroid receptor alpha-THR $\alpha$, Thyroid receptor beta-THR $\beta$, deiodinase type IDIO1, and deiodinase type II-DIO2) were measured in both species, and relationships between the endpoints were evaluated to see if associations exist between thyroid endpoints at multiple biological levels. Histological evaluation of the thyroid tissue indicated hyperstimulation (as indicated by increased thyroid epithelial cell height and partially depleted colloid) in smallmouth bass and brown bullhead sampled in the spring. Despite observed histologic alterations, changes in thyroid gland histology did not coincide with changes in concentrations of circulating thyroid hormones. However, gene transcript abundance of THR $\alpha$ was negatively correlated with TSH and T3 while levels of DIO2 were positively correlated with TSH and T3 in smallmouth bass, suggesting these genes are sensitive and stable indicators for thyroid status. The results 
demonstrate the importance of using a multi-tiered approach to evaluate the potential risks of EDCs on the teleost thyroid system, as well as the importance of choosing sensitive species and accounting for seasonality.

\section{Introduction}

Numerous naturally occurring and synthetic chemicals can interact with the endocrine system of wild fish, which can lead to a disturbance of hormone metabolism or hormoneregulated cellular and physiological processes. The thyroid system is one of the major targets of endocrine disrupting chemicals (EDCs). In the Great Lakes, there are several water-borne and sediment associated contaminants that are suspected to disrupt thyroid function, such as bisphenol A (BPA) and various polybrominated diphenyl ethers (PBDEs) (Lee et al. 2015). These chemicals can mimic or perturb the effects of endogenous hormones, modify hormone receptor levels, alter the metabolism of normal hormone synthesis, and interfere with the transport binding proteins which deliver hormones to their intended tissues (Wade et al. 2002; Ishihara et al. 2003; Brown et al. 2004; Boas et al. 2006; Blanton and Specker 2007). In the presence of EDCs, fish have been shown to have decreased growth and fertility, increased larval mortality, and altered swimming activity (Stephens et al. 1997; Wu et al. 2003; Yu et al. 2010; Noyes and Stapleton 2014) through imbalance of plasma hormone levels or changes in the structure of the thyroidal tissues (thyroid hypertrophy, hyperplasia). The central control of thyroid hormone in fish is limited to the production and secretion of T4, which is transformed into the biologically active T3 in peripheral tissues, mainly the liver which is essential for reproductive activities. Although many fish studies have utilized thyroid hormone levels and thyroid histology as biomarkers of EDC exposure, the mechanisms involved in the alteration of the thyroid function in fish are not fully understood. This lack of information is confounded 
further by the fact that data on the effect of chemical pollution on the thyroid have been inconsistent and depend greatly on the nature of the chemicals involved and the species studied. The best approach to understanding the effects of complex mixtures on the thyroid of wild fish is to use a suite of biomarkers that assess cumulative impacts on the thyroid.

Biomarkers at the molecular, subcellular, and tissue levels have been used to determine specific thyroid responses to contaminant stressors. Molecular markers (gene expression) are often reflective of recent or acute exposure (within minutes to hours), as gene transcription is sensitive to endogenous and exogenous impacts and fluctuates constantly. Tissue-level changes are histologically apparent manifestations of an exposure that may have occurred anywhere from weeks to months ago (Teh et al. 1997). Manifestations of thyroid disruption at the subcellular (hormonal) level represent an intermediate effect between the molecular- and tissue-level effects because hormonal responses occur more slowly than molecular changes, but more quickly than tissue changes. Together, these integrative biomarkers provide a better evaluation of thyroid health than a single parameter and are important because they often relate to known impairments. However, they are dynamic and can be influenced by factors including age, gender, diet, season, and species (Rolland 2000) which are often difficult to account for in field studies.

Most of the research on the teleost thyroid focuses on the use of model organisms such as fathead minnow (Pimephales promelas), zebrafish (Danio rerio), rainbow trout (Oncorhynchus mykiss), and medaka (Oryzias latipes). While information on these species has greatly contributed to our understanding of mechanisms, similar information for wild fish species exposed to environmentally-relevant concentrations of contaminants is still lacking. For this reason, two wild-caught species were targeted for analyses. The species were based on their representation of either a benthic or pelagic community. Brown bullhead (Ameiurus nebulosus) 
is an opportunistic benthivore with a propensity to absorb contaminants from food and sediments. Smallmouth bass (Micropterus dolomieu) is a top pelagic carnivore of commercial and recreational importance. It has been demonstrated that smallmouth bass (SMB) is a reliable sentinel species for monitoring effects of estrogenic contaminants in the Great Lakes (Blazer et al. 2014; Blazer et al. 2018) as it is well documented that SMB respond by induction of vitellogenin and testicular oocytes (intersex) in males (Blazer et al. 2007; Blazer et al. 2012; Kadlec et al. 2017). Brown bullhead (BBH) have also been used in the Great Lakes watershed as an indicator species, particularly in the evaluation of the presence of liver and skin tumors and other adverse effects (Smith et al. 1989; Baumann et al. 1996; Rafferty et al. 2006; Blazer et al. 2009a,b). These species have the potential to be valuable models for thyroid disruption research. The objectives of this study were to first determine associations among the various thyroid-related endpoints in smallmouth bass and brown bullhead from Great Lakes Areas of Concern. Specifically, we aimed to investigate histological features of thyroid follicles and to determine whether morphological changes are associated with the functional activity of the follicles. Secondly, we investigated whether hepatic gene expression could help explain histologic or hormonal responses. A second objective was to evaluate brown bullhead and smallmouth bass as indicator species for thyroid endocrine disruption. An auxiliary objective was to determine if a multiplex assay using the Lumine ${ }^{\circledR} \mathrm{xMAP}^{\circledR}$ technology could be validated for these species. Radioimmunoassay is the method generally used for fish thyroid hormone analyses. However, this requires radiolabeled reagents which were not possible for us to use.

\section{Methods}

Site Information 
Seven sample sites were chosen (Figure 1) to represent a mix of urban and agricultural land uses that are detailed in Choy et al. (2017). These sites are those known to historically have fish health issues and documented legacy contaminants as well as chemicals of emerging concern (CECs) (Rafferty et al. 2009; Lee et al. 2012; Lee et al. 2015; Baldwin et al. 2016; Choy et al. 2017; Elliot et al. 2017; Blazer et al. 2018). From these 7 sites, only fish with attainable thyroid sections were used (Table 1). Brown bullhead were collected at three sites in Spring 2012. These included two sites within the Rochester Embayment AOC and one site within the Detroit River. Within the Rochester Embayment AOC, only males from Long Pond were used in analysis because histological data was unavailable for females from that site. In the spring, smallmouth bass were collected at sites in River Raisin and the Fox River. In the fall, SMB were collected at two sites in the St. Louis River.

\section{Field Methods}

Attempts were made to collect 20 mature fish, defined as greater than $250 \mathrm{~cm}$ in length, of each of the two species. Fish were euthanized in a holding tank containing a lethal dose of tricaine methanesulfonate (MS-222, Finquel, Argent Laboratories, Redmond, WA). Handling and euthanasia protocols were approved by the USGS, Leetown Science Center, Institutional Animal Care and Use Committee. Fish total length was measured to the nearest millimeter and weight to the nearest gram. Blood was collected from the caudal vein or dorsal aorta with a sodium heparinized (Fisher Scientific, Pittsburgh, PA) syringe. Plasma fractions were isolated by centrifugation at $3,000 \mathrm{xg}$ for 10 minutes and stored at $-80^{\circ} \mathrm{C}$ until analysis of THs. Small sections of liver were collected and preserved in RNA-later ${ }^{\circledR}$ for gene expression analysis. Pieces of pharyngeal and gill arch areas were placed in Z-fix for histological analyses. 


\section{Thyroid Histology}

Sections from regions of the head generally containing thyroid tissues were embedded into paraffin, sectioned at $5 \mu \mathrm{m}$, and stained with hematoxylin and eosin. Thyroid histology samples were assessed morphologically following methods used by Gilroy et al. (2012). At least ten thyroid follicles per fish were selected and digitally measured to quantify potential indicators of thyroid activity: thyroid epithelial cell height (TECH), ratio of thyroid epithelial cell area to colloid area (TECA:colloid), and percent colloid vacuolation. Light microscopy was performed at the 20x, 40x, or 63x magnification level with an Axio Observer inverted microscope equipped with an AxioCam 503 color imaging camera (ZEISS, Jena, Germany). The measurements were taken using the free software tool Image J I.44 (National Institutes of Health, Bethesda, MD) to quantify observed alterations.

Thyroid epithelial cell hypertrophy was evaluated by TECH. The measurement of TECH (in $\mu \mathrm{m}$ ) was reported as the mean of four cardinal point estimates per follicle, i.e. the average of 40-68 follicular cell height measurements for each fish. The cardinal points were chosen based on having visible nuclei, indicating a proper cross section (Figure 2).

Colloid content of the follicles was used as an indicator of hormonal secretion. The percentage of colloid vacuolation in a follicle was calculated and recorded, with values of 0 and $100 \%$ representing extremes of colloid-replete and colloid-exhausted follicles, respectively. Percent colloid vacuolation was calculated by dividing droplet area by total colloid (Figure 3). Total colloid was calculated by subtracting the droplet area from colloid + droplet area. The TECA:colloid ratio was calculated as the area of the follicular epithelial cells divided by the area of the colloid in follicles containing colloid. 


\section{Gene Expression}

Transcriptome development and methods for transcript abundance have been previously described by Hahn (2012). Briefly, tissue lysate was prepared from liver samples. Approximately 17 - $23 \mathrm{mg}$ of liver tissue was homogenized in $400 \mu \mathrm{l}$ of TRK lysis buffer (Omega Biotech, Norcross, GA) in a tissue lyser (Qiagen, Valencia, CA) with $5 \mathrm{~mm}$ stainless steel balls (Boca Bearings, Boynton Beach, FL) at 30 hertz for 8 minutes. Samples were centrifuged at 16,100 RCF for 10 minutes and the supernatant was removed. Tissue lysate was sent to the University of Pittsburgh Genomics and Proteomics Core Laboratory (Pittsburgh, PA) for mRNA expression analysis. Annotated sequence data for each gene was orientated and trimmed to correspond to coding regions using results from BLASTx searches. Custom CodeSets were designed by Nanostring Technologies (Seattle, WA), which included a total of 50 genes, including housekeeper genes, and transcript abundance was quantified using nCounter Analysis ${ }^{\circledR}$ (NanoString Technologies, Seattle, WA), which uses molecular barcoding and multiplex technology to quantify transcripts. Genes of interest included in this study were those related to thyroid function (THR $\alpha$, THR $\beta$, DIO1, DIO2) as well as housekeeping genes (Table 2), although deiodinase levels were only available for SMB.

The nSolver Analysis Software (v2.0) was used for quality control of gene expression data. Negative controls, as included by Nanostring quality control protocol, with high average counts (values ranging from 7-37) were removed. The geometric mean plus three standard deviations of negative control probes was subtracted from each sample to account for background signal. Reference (housekeeping) genes were used for normalization. Housekeeping genes differed between species as necessary to account for variation in each custom CodeSet. Housekeeping genes were selected to span average counts (low, medium and highly expressed) 
and \% Coefficient of Variation values of all data collected and included Elongation Factor $1 \alpha$, Eukaryotic Translation Initiation Factor 3D, Hypoxanthine Phosphoribosyltransferase 1, Phosphoenolpyruvate Carboxykinase, RNA binding motif protein Xlinked 2, Ribosomal Protein L8, and Tata Box Binding Protein. The geometric mean of the housekeeping genes was used to calculate a scaling factor which was applied to all data.

\section{Hormonal Response Measurement}

\section{Thyroxine and Triiodothyronine}

The multiplex system used for the simultaneous measurement of plasma TT3 and TT4 was Luminex ${ }^{\circledR}$ xMAP® technology. Plasma TT3 and TT4 concentrations were measured in a competitive assay using a Milliplex ® Map Rat Thyroid Hormone Panel (EMD Millipore, Billerica, MA). The panel contains analyte-specific color-coded magnetic beads that are conjugated with capture antibodies. Unlabeled hormones in the sample compete with labeled antibodies (HRP) for the capture antibodies. Biotinylated detection antibodies are added followed by an incubation step with streptavidin-phycoerythrin. In the absence of analytes in the sample, the labeled T3-T4 (HRP) will bind to the bead and can be detected by the biotinylated detection antibodies. The signal is inversely proportional to the amount of analyte in the sample. The computer program, Bio-Plex Manager ${ }^{\mathrm{TM}}$, interpolates the concentration of the sample from the standard curve graph.

Three plates were used to run a total of 87 plasma samples. Samples were run in duplicate using the optimized sample preparation and instrumental analytical method. Samples with a $\%$ Coefficient of Variation $>12$ were reassayed. Samples below detectable levels were diluted with a lower dilution factor (1:4 vs. 1:6) and reassayed to fall within the range of the curve values. 
The Milliplex bead panels used for this competitive assay were originally developed for quantification of rat thyroid hormones. Therefore, the assay was tested for sensitivity and specificity for THs in SMB and BBH plasma. Sensitivity was determined for each hormone and corresponded to the lowest detectable hormone concentration in the range of the standard curve in the multiplex assay. The sensitivity of the multiplex assay was 156.3 and $3,125 \mathrm{pg} / \mathrm{mL}$ for T3 and T4, respectively. Specificity is the ability of the assay antibody to distinguish between the analyte of interest and other components and was evaluated by comparing spike recovery of the serum matrix to the spike recovery of charcoal-stripped pooled fish plasma at six concentrations of diluted kit standards for T3 and T4. A charcoal stripping procedure, outlined in Appendix A, was used to remove endogenous analytes and to control for non-specific interference in spiked standards. Acceptance criteria for specificity requires spike recovery to be within $25 \%$ of the lower limit of quantitation and the upper limit of quantitation (U.S. FDA 2018). Specificity, as determined by recovery of known amounts of $\mathrm{T} 3$ and $\mathrm{T} 4$, respectively in charcoal stripped $\mathrm{BBH}$ plasma, was $102 \%$ and $124 \%$ for 312.5 and $5000 \mathrm{pg} / \mathrm{mL}$ of $\mathrm{T} 3$, respectively while the values for T4 were extremely high or above the range of detection (Table 3). In treated SMB plasma, recovery of $\mathrm{T} 3$ was $145 \%$ and $117 \%$ for 312.5 and $5000 \mathrm{pg} / \mathrm{mL}$ while the values for T4 were again high or above range.

Two types of blank controls were tested alongside each standard to monitor potential matrix effects. The first type of blank control was assay buffer provided by the kit and was used to monitor background according to kit instructions. The second type of blank control was experimental, as it was charcoal-stripped plasma diluted in assay buffer; this treated blank control did not contain any standard and was used to monitor potential matrix effects in the plasma. The concentration of T3 in treated blank controls for both species were below the level 
of detection. However, a high detectable concentration of T4 was recovered in treated blank controls. Matrix effects were also monitored by spiking three dilutions of charcoal stripped plasma with known concentrations of hormones. It appears that $\mathrm{TH}$ measurements were not independent of dilution factor, indicated by the increase in T3 concentration with increasing dilution factor (Table 4). Method precision was evaluated using the coefficients of variation (CVs) within (intra-) and between (inter-) assays and were determined to be below $15 \%$ in this study.

\section{Thyroid Stimulating Hormone}

The determination of TSH in plasma was performed using competitive inhibition ELISA kits (Cusabio, Wuhan, China) specific for Fish TSH. Absorbance was measured at $450 \mathrm{~nm}$ in a SpectraMax ${ }^{\circledR}$ M4 microplate reader (Molecular Devices, San Jose, CA). The TSH in the sample competes with biotin-conjugated TSH for binding onto a limited number of pre-coated TSH antibody sites in the microplate wells. Three 96-well plates precoated with a TSH-specific antibody were used to quantify TSH concentrations in SMB and BBH plasma. For all assays, 50 $\mu 1$ of standards, internal controls, and plasma samples were added to each well of the plate according to the assay plate map. Next $50 \mu \mathrm{l}$ of the Biotin-conjugated TSH was added to each well (not to Blank well). Then $50 \mu$ l of corresponding HRP-avidin was added to each well (not to Blank well), and the plates incubated at room temperature for 1 hour. Plates were washed and aspirated, and $50 \mu \mathrm{l}$ of a substrate solution was added to each well. The addition of $50 \mu \mathrm{l}$ of stopping solution into each well stopped the reaction so that the optical density of the wells could be read. Non-specific binding was accounted for by subtracting blank absorbance from each reading. Standard curves were generated and a 4-parameter logistic curve was used to determine hormone concentrations in plasma samples. 
The ELISA was tested for sensitivity and specificity for TSH in SMB and BBH plasma. The sensitivity for the Cusabio Fish TSH ELISA was between $2.5 \mu \mathrm{IU} / \mathrm{mL}$ and $40 \mu \mathrm{IU} / \mathrm{mL}$. Method precision, evaluated by intra- and inter-assay CVs, was determined to be below $15 \%$. Specificity results in Table 5 show that spiking charcoal-stripped sample matrix with kit standard resulted in an over-recovery of the TSH. For this reason, the assay only allows a relative quantification of TSH.

\section{Data Analysis}

The means of all sites were compared by using one-way analysis of variance (ANOVA) to assess significant effects of histological and hormonal data. The assumptions of normality and homogeneity of variance were verified using Levene's test. Tukey's HSD test was performed to analyze all possible pair-wise comparisons between means of all sites, signaling differences between sites. Attempts were made to model dependent variables, but none of the candidate explanatory variables were statistically significant. Pearson's correlation analysis was used to find the strength of association between all the variables analyzed after verifying assumptions of normality. A p $\leq 0.05$ was considered to define statistically significant results. Statistical analysis was performed using R statistical package (R Core Development Team 2016) for Windows.

\section{Results}

\section{Thyroid Histology}

\section{Qualitative Morphology}

Thyroid data exists for $\mathrm{BBH}$ at three sites in the spring season only. In general, BBH thyroid tissue was composed of a moderate number of spherical or ellipsoid follicles. The follicular epithelium was generally a single layer of cuboidal or columnar cells with round, centrally located nuclei and prominent nucleoli. There were observed instances of hypertrophy 
and hyperplasia (Figure 4 and 5). Colloid within the lumen was moderately to extensively vacuolated (Figure 6), with $28 / 38 \mathrm{BBH}$ having at least $25 \%$ vacuolation occurring in the follicles. Some follicles were large and devoid of colloid (Figure 7).

Thyroid sections were available for SMB sampled both in the spring and in the fall. The morphology of the follicles of the SMB sampled in the spring varied widely. The follicles of fish from Fox River generally were small and appeared irregular in form (Figure 8) with undefined epithelial cell walls. In the follicles of fish from River Raisin, there were many signs of hypertrophy and fewer signs of hyperplasia. Similar to the spring BBH follicles, many spring SMB follicles were highly vacuolated (Figure 9a) with 12/25 fish showing at least 25\% vacuolation (colloid depletion).

In general, the thyroid follicles of SMB collected in the fall were normal. The epithelium was one cell thick, composed of flattened squamous cell types with depressed, basally located nuclei and abundant colloid (Figure 9b). The colloid stained brightly with eosin and was relatively homogenous. A commonly encountered pattern in the fall SMB was large, colloidfilled follicles with thin walls. Only 4/30 fish had highly vacuolated colloid in the fall. One limitation of the histology component of this project is the diffuse nature of thyroid tissue in fish, which makes capturing sections difficult.

\section{Quantitative Morphology}

The follicular epithelial cell layer for BBH ranged from 6.7 to $14.4 \mu \mathrm{m}$ in thickness. Thyroid epithelial cell height did not differ by sex within sites $(\mathrm{p}>0.05)$ or between sites (Figure 10). One significant difference was found in percent colloid vacuolation among females, with percent colloid vacuolation of female BBH from Rochester Embayment (Irondequoit Bay) being 
significantly greater than that of females from the Detroit River $(\mathrm{p}=0.002$, Figure 11). No intersite difference was found in the mean TECA:colloid ratio of $\mathrm{BBH}(\mathrm{p}>0.05$, Figure 12).

Histological data for SMB were analyzed by season. Thyroid epithelial cell height for smallmouth bass sampled in the spring ranged from 5.2 to $12.5 \mu \mathrm{m}$ while TECH for smallmouth bass sampled in the fall ranged from 3.6 to $11.0 \mu \mathrm{m}$. No significant intersite difference was found in the mean TECH of male SMB or in female SMB between sites of the same season. Also, there was no significant difference in TECA:colloid ratio or percent colloid vacuolation when comparing sites within the same season. However, when the sites were compared across seasons, some significant differences were evident. Post hoc analyses showed significant differences between spring sites (River Raisin and Fox River) and fall sites (St. Louis Upper Estuary and St. Louis Middle Estuary) ( $<$ 0.05). The same relationship was true for the ratio of TECA:colloid, with significant differences evident between spring and fall sites $(\mathrm{p}<0.05)$. Fall sites did not differ significantly compared to spring sites with regard to percent colloid vacuolation.

Correlations between the histological criteria (TECH, percent vacuolation, and TECA:colloid area) were examined by Pearson's correlation analysis and are reported in Tables 6 and 7. Positive relationships were found between histological variables in both species. In SMB, TECH and percent vacuolation were positively correlated $(\mathrm{R}=0.51, \mathrm{p}<0.0001)$. The TECA:colloid ratio was strongly correlated with TECH in SMB $(\mathrm{R}=0.69, \mathrm{p}<0.0001)$ and $\mathrm{BBH}$ $(\mathrm{R}=0.57, \mathrm{p}=0.0002)$ and positively correlated with percent vacuolation in $\mathrm{SMB}(\mathrm{R}=0.46, \mathrm{p}=$ $0.0004)$ and $\mathrm{BBH}(\mathrm{R}=0.35, \mathrm{p}=0.03)$.

Gene Expression 
Thyroid receptor levels alpha and beta (THR $\alpha, \operatorname{THR} \beta)$ were available for both species while deiodinase levels (DIO1, DIO2) were only available for SMB. In SMB, the expression level of THR $\alpha$ in the liver was negatively correlated with T3 $(\mathrm{R}=-0.47, \mathrm{p}<0.001)$ and TSH $(\mathrm{R}$ $=-0.48, \mathrm{p}<0.001)$. The expression levels of DIO2 were positively correlated with $\mathrm{T} 3(\mathrm{R}=0.53$, $\mathrm{p}<0.001)$ and TSH $(\mathrm{R}=0.66, \mathrm{p}<0.001)$ concentrations in SMB. The mRNA expression for THR $\alpha$ and THR $\beta$ in BBH did not correlate with any thyroid parameters. In SMB, DIO2 levels differed significantly in fish sampled in the spring compared to fish sampled in the fall. For example, Fox River and River Raisin were statistically different than St. Louis Middle Estuary (p $<0.05)$.

\section{Hormonal Response Measurements}

Plasma levels of TT3 and TT4 showed large variations between groups and species. In SMB plasma, TT3 and TT4 concentrations ranged from $5.9-31.4 \mathrm{ng} / \mathrm{mL}$ and $41.2-199.7 \mathrm{ng} / \mathrm{mL}$, respectively. Analysis of BBH plasma measured TT3 and TT4 levels at 0.28-19.7 and 48.4-241.4 $\mathrm{ng} / \mathrm{mL}$, respectively. There were no sex differences in TH levels within each species. The TT4 did not have a significant relationship with any histologic or genetic parameters. The TT3 showed a strong positive relationship with TSH and the T3:T4 ratio in both species. The values for BBH TSH ranged from 3.4 to $10.1 \mu \mathrm{IU} / \mathrm{mL}$ while the values for SMB TSH ranged from 4.9 to $15.3 \mu \mathrm{IU} / \mathrm{mL}$. Pearson's correlation analysis showed that TSH was strongly correlated with T3 $(\mathrm{R}=0.75, \mathrm{p}<0.001)$ as well as the T3/T4 ratio (Table 6 and 7) in both species.

Significant seasonal differences in thyroid hormones were apparent. Fish from both River Raisin and Fox River (sites sampled in the spring) showed significantly different levels of TSH when compared to that of fish sampled from St. Louis sites in the fall $(\mathrm{p}<0.01)$. Some significant seasonal differences were also apparent for T3 levels. The level of T3 differed in fish 
from both spring sites when compared to St. Louis Middle Estuary ( $\mathrm{p}<0.05)$. No statistically significant differences were evident in levels of T4.

\section{Discussion}

Thyroid histopathology is a robust indicator of thyroid disruption especially when used in tandem with other biomarkers. In the present study, we employed three histologic endpoints to evaluate thyroid status: TECH, percent colloid vacuolation, and the ratio of TECA to colloid area. In 'normal' fish thyroid tissue, epithelial cells are usually cuboidal or squamous in form and the colloid smooth with some vacuolation of the periphery associated with uptake of colloid (Leatherland and Down 2001). In the pathologic condition, epithelial cells are columnar (hypertrophied), there is extensive vacuolation (colloid depletion), and the follicles may be hyperplastic or take on an irregular shape. In this study, we observed many instances of the pathologic condition in SMB and $\mathrm{BBH}$ that has been described previously in salmon caught from Great Lakes sites polluted with huge amounts of EDCs (Leatherland and Sonstegard 1980; Moccia et al. 1981). Whether the histologic alterations in the present study can be attributed to chemicals or other factors is unclear. Although thyroid disrupting chemicals such as pesticides, PAHs, and PBDEs were detected at our sites (Table 8), we did not see trends between thyroid parameters and these contaminants. That is not to say that some of these chemicals cannot effect change at low doses. Some EDCs, like BPA and atrazine included in this study, have a nonlinear relationship between dose and effect resulting in greater effects at very low or very high concentrations (Vandenberg et al. 2012). These effects are known as nonmonotonic responses and are remarkably common in studies of natural hormones and EDCs, although many documented effects focus on the reproductive system (Vandenberg et al. 2012). Unfortunately, for these chemicals there is no broad consensus on the definition of "low dose" and information 
as it relates specifically to the teleost thyroid remains limited. In addition, the concentrations documented to have low-dose effects are higher than the concentrations documented in this study. For example, in laboratory experiments, the PBDE contaminant, Triphenyl phosphate, has been shown to disrupt thyroid regulation and hormone synthesis in cultured cells and in zebrafish larvae at doses as low as $10 \mu \mathrm{g} / \mathrm{L}$ (Liu et al. 2013; Kim et al. 2015). In this study, however, the highest detected concentration of Triphenyl phosphate was $0.04 \mu \mathrm{g} / \mathrm{L}$. Similarly, the herbicide Metalochlor was shown to alter gene thyroid-related gene transcription in juvenile medaka at 10 $\mu \mathrm{g} / \mathrm{L}$ (Jin et al. 2010), which is approximately ten times greater than the highest concentration of Metolachlor detected in this study. Nieves-Puigdoller et al. (2007) observed reduced plasma TH concentrations in fish exposed to $100 \mu \mathrm{g} / \mathrm{L}$ of atrazine, but there are mixed results on effects of lower concentrations (Rohr and McCoy 2010). In general, not enough data are available to discuss the relationships between these concentrations and the real exposures in our species. At this time, the effects we report here, particularly in regard to histopathology, cannot be causally linked to contaminants and more research will be needed.

Despite observed histologic alterations in thyroid follicle, changes in concentrations of circulating THs did not occur as expected. Histologic alterations may indicate hyperstimulation of the follicles, and this evidence usually coincides with significant changes in plasma TH levels. For example, if the secretion of THs is inhibited by the presence of an environmental substance, the resultant decrease of plasma T4 levels gives rise to a compensatory increase in TSH secretion. The elevated TSH levels will stimulate follicular synthesis of thyroglobulin resulting in an increase in cell size (and increased cell replication) giving rise to hypertrophy and hyperplasia of the epithelial cells. Moccia et al. $(1981,1986)$ first reported this evidence in predatory fish and herring gulls from Great Lakes sites contaminated with PAHs. Observations 
of thyroid gland hypertrophy and follicle cell hyperplasia suggested that thyroid abnormalities associated with contaminant exposure resulted from hypothyroidism, i.e. low levels of TT3 and TT4 (Moccia et al. 1981, 1986). These thyroid gland alterations were suggestive of HPT axis activation from the feedback effects of low concentrations of circulating THs (Moccia et al. 1981, 1986). In this study, we investigated whether hormone levels correlate with histologic parameters as they did in Moccia's study. One hypothesis that explores this, for example, is that perhaps fish with hypertrophy and hyperplasia would also show low levels of TT3 and TT4 (hypothyroidism). Many of the chemicals known to adversely affect thyroid function, such as arsenic, PCBs, and perchlorate (Patino et al. 2003; Brown et al. 2004; Schnitzler et al. 2011; Simmons et al. 2014; Sun et al. 2016), were not analyzed and others were observed at low levels (Table 8). Additionally, the plasma hormone assays could not be validated for these species and hence the TH concentrations reported here may not be accurate.

This is the first study to use multiplex array in the measurement of circulating thyroid hormones in SMB and BBH, which makes direct comparisons with other studies difficult. Published studies to date employed enzyme-linked immunosorbent assay (ELISA) or radioimmunoassay (RIA) to measure THs in fish blood or tissue extracts. Previous RIA work by Iwanowicz et al. (2012) has reported circulating levels of TT3 and TT4 in wild-caught brown bullhead from a polluted site over several seasons at 4.5-6 and 2.1-4.5 ng/mL, respectively, which generally do not agree with the values measured here by multiplex array (TT3: 0.28-19.7 ng/mL; TT4: 48.4-241.4 ng/mL). Similarly, brown bullhead collected from the Wheatley Harbor AOC reported much lower levels of TT3 and TT4 at $0.9-2.3 \mathrm{ng} / \mathrm{mL}$ and 3.7-5.2 ng/mL (Gilroy et al. 2012) than the levels reported here. In this study, TT3 and TT4 concentrations for SMB ranged from 5.9-31.4 ng/mL and 41.2-199.7 ng/mL, respectively. To date, TH levels are not 
documented in the literature for SMB. However, studies of THs in largemouth bass, a freshwater species in the Micropterus family, report average TT3 and TT4 levels at approximately 50-550 $\mathrm{ng} / \mathrm{mL}$ and 3.5-13.5 ng/mL, respectively. The discrepancies in TH levels might be attributed to the lack of specificity of the assay in this study.

Despite discrepancies between measured and documented hormone levels, the T3:T4 ratio was positively correlated with T3 levels and negatively correlated with T4 levels in both species. The T3:T4 ratio provides an indirect measure of extrathyroidal conversion of T4 to T3 by deiodination (Brar et al. 2010) and may be a more useful endpoint than the analysis of individual hormone levels. In addition, the positive correlation between T3:T4 ratio and DIO2 levels are in agreement with previous studies (Brar et al. 2009; Truter et al. 2016).

Hepatic gene expression can provide information on potential adverse effects mechanisms occurring as a result of exposure to chemical mixtures. Previously, it has been demonstrated that the TR genes could be regulated by TH levels. Whether these genes are induced or repressed depends on the tissue, receptor isoform, and taxon (Lema et al. 2009). There have been two isoforms of TRs reported in fish (THR $\alpha$ and THR $\beta$ ), which act as ligandactivated transcription factors inducing or repressing the transcription of genes containing a thyroid response element. In the present study, the expression level of THR $\alpha$ in the liver was negatively correlated with T3 and TSH in SMB. This result was unexpected, since the protein encoded by THR $\alpha$ is a nuclear hormone receptor for T3 and this gene is typically induced by T3 in the liver. In the absence of T3, the unliganded receptors interact with co-repressor proteins, which inhibit transcription. The binding of T3 to TRs causes a conformational change, releasing co-repressors and recruiting co-activators, such as histone acetyltransferases, which modulate chromatin structure. This generally leads to a transcriptionally active conformation on the 
chromatin around thyroid responsive promoters. In a study examining TR function, fathead minnow treated with exogenous T3 had elevated transcript levels for both isoforms in the liver (Lema et al. 2009). Similarly, transcripts for THR $\alpha$ and THR $\beta$ expressed in eel hepatocytes were also induced by T3 and T4 (Kawakami et al. 2006). Contrary to these findings, our results show that THR $\alpha$ has an inverse relationship with T3 in SMB from these Great Lakes sites.

Some previous studies have suggested that most thyroid disruptors may not directly interact with TRs, but rather affect other elements within the thyroid signaling pathway. Iodothyronine deiodinases, the key enzymes in the activation and inactivation of THs, have been suggested as suitable biomarkers for thyroid disruption because of their essential function in controlling thyroid homeostasis (Orozco and Valverde 2005). Previous studies have indicated that the deiodinase transcripts were sensitive molecular biomarkers for thyroid disruption in fish that had been exposed to environmental contaminants (Li et al. 2009; Picard-Aitken et al. 2007; Shi et al. 2009). In this study. the expression levels of DIO2, the predominant deiodinase in the fish liver that is responsible for the synthesis of T3, was positively correlated with T3 as well as TSH concentrations in SMB. This finding makes sense because among the IDs, DIO2 is the isoform that shows a finer regulation, i.e. higher sensitivity and response to T3 in the liver. This supports the current notion that DIO2 is a sensitive and stable indicator for thyroid status.

In this study, we evaluated thyroid biomarkers of response in brown bullhead and smallmouth bass and assessed these species' utility as bioindicator species. These species have demonstrated different sensitivities to pollution in the past, likely due to factors such as physiological attributes and habitat usage. For example, brown bullhead have demonstrated sensitivity to the effects of exposure to EDCs that cause skin and liver tumors, but their sensitivity to estrogenic EDCs is less obvious (Blazer et al. 2009a; Blazer et al. 2009b; Blazer et 
al. 2014). Smallmouth bass on the other hand are more sensitive to exposure to estrogenic EDCs that cause reproductive endocrine disruption (Blazer et al. 2007; Blazer et al. 2012; Blazer et al. 2014). Both species have been used in ecotoxicological studies evaluating adverse effects, but few have used them to study thyroidal responses. Interestingly, Iwanowicz et al. (2012) reported evidence of PCB-induced thyroid disruption in largemouth bass and brown bullhead from a Great Lakes AOC in the spring season, but not the summer or fall, suggesting that TH disruption may only be evident when the thyroid is physiologically activated. Our results support this notion, since both species sampled in the spring showed some histopathologic signs of thyroid disruption, while fish in the fall tended to have normal follicles. It is possible that these species may be most useful as bioindicators for thyroid disruption at specific time points, such as during the spawning period, when the thyroid may be the most susceptible to disruption. At this time our results do not clearly indicate whether these species are suitable bioindicators for thyroid disruption since there was such high variability in the histologic data. Baseline information on normal thyroid conditions at specific time points for these species must first be established and this is a potential avenue for future research.

\section{Conclusion}

The current study aimed to investigate thyroid biomarker responses and associations between biomarkers in two wild fish species from the Great Lakes as a step toward understanding the impacts of existing contaminants on a critical endocrine system. In this study we observed histologic evidence of thyroid disruption such as hypertrophy, hyperplasia, and colloid depletion, but no corresponding increases or decreases in hormonal or molecular responses that could help explain mechanisms. While we were able to identify some relationships, such as positive correlation between TSH and T3, the differences in measured 
variables showed no corresponding differences in chemical profiles. Answers are not definitive at this time and more data will be needed before attributing thyroid responses to current-day exposures of contaminants. Smallmouth bass and brown bullhead may be most useful as bioindicators for thyroid disruption at specific time periods, such as during spawn, when the thyroid is physiologically active and most susceptible to disruption. The results provided here demonstrate that a multi-tiered approach is of great importance to comprehensively evaluate the potential risks of emerging contaminants on the teleost thyroid system. 


\section{Literature Cited}

Baldwin, A.K., S.R. Corsi, L.A. De Cicco, M.A. Lutz, D.J. Sullivan, K.D. Richards. (2016). "Organic contaminants in Great Lakes tributaries: prevalence and potential aquatic toxicity." Science of the Total Environment 554-555, 42-52.

Blazer, V.S. et al. (2007). "Intersex (testicular oocytes) in smallmouth bass from the Potomac River and selected nearby drainages." Journal of Aquatic Animal Health 19(4):242-53.

Blazer, V.S. et al. (2009a). "Assessment of the "tumors or other deformities" beneficial use impairment in brown bullhead: I. Orocutaneous tumors.” Journal of Great Lakes Research 35:517-526.

Blazer, V.S. et al. (2009b). "Assessment of the 'tumors and other deformities' beneficial use impairment in brown bullhead: II. Liver tumors." Journal of Great Lakes Research 35:527-537.

Blazer, V.S. et al. (2012). "Reproductive endocrine disruption in smallmouth bass (Micropterus dolomieu in the Potomac River basin: spatial and temporal comparisons of biological effects." Environmental Monitoring and Assessment 184(7): 4309-4334.

Blazer, V. S. et al. (2014). "Monitoring of wild fish health at selected sites in the Great Lakes basin — methods and preliminary results." U.S. Geological Survey Open-File Report, 2014-1027, 31 https://doi.org/10.3133 /ofr20141027.

Blazer, V.S., H.L. Walsh, C.H. Shaw, L.R. Iwanowicz, R.P. Braham, P.M. Mazik. (2018). "Indicators of exposure to estrogenic compounds at Great Lakes Areas of Concern: species and site comparisons.” Environmental Monitoring and Assessment 190(10):577.

Brown, S.B. B.A. Adams, D.G. Cyr, J.G. Eales. (2004). "Contaminant effects on the teleost fish thyroid." Environmental Toxicology and Chemistry 23(7):1680-1701.

Choy, S.J., M.L. Annis, J. Banda, S.R. Bowman, M.E. Brigham, S.M. Elliot, D.J. Gefell, M.D. Jankowski, Z.G. Jorgenson, K.E. Lee, J.N. Moore, W.A. Tucker. (2017). “Contaminants of emerging concern in the Great Lakes Basin: a report on sediment, water, and fish tissue chemistry collected 2010-2012.” U.S. Fish and Wildlife Service, Biological Technical Publication BTP-R3017-2013.

Elliot, S.M., M.E. Brigham, K.E. Lee, J.A. Banda, S.J. Choy, D.J. Gefell, T.A. Minarik, J.N. Moore, Z.G. Jorgenson. (2017). "Contaminants of emerging concern in tributaries to the Laurentian Great Lakes: I. patterns of occurrence.” PLOS ONE 12(9), e0182868 21p.

Jin, Y., R. Chen, L. Wang, F. Zhengwei. (2010). "Effects of metolachlor on transcription of thyroid system-related genes in juvenile and adult Japanese medaka (Oryzias latipes)." General and Comparative Endocrinology 170(3):487-493.

Kawakami, Y., D.H. Shin, T. Kitano, S. Adachi, K. Yamauchi, H. Ohta. (2006). "Transactivation activity of thyroid hormone receptors in fish (Conger myriaster) in response to thyroid hormones." Comparative Biochemistry and Physiology B 144(4):503-509. 
Kim, S., J. Jung, I. Lee, D. Jung, H. Youn, K. Choi. (2015). “Thyroid disruption by triphenyl phosphate, an organophosphate flame retardant, in zebrafish (Danio rerio) embryos/larvae, and in GH3 and FRTL-5 cell lines." Aquatic Toxicology. 160:188-196.

Leatherland, J.F. and Down, N.E. (2001). "Tumours and related lesions of the endocrine system of bony and cartilaginous fishes." Fish and Fisheries 2:59-77.

Lee, K.E., S.K. Langer, M.A. Menheer, D. Gefell. (2015). "Chemicals of emerging concern in water and bottom sediment in Great Lakes Basin, 2012 - Collection methods, analytical, methods, quality assurance, and study data.” U.S. Geological Survey Data Series 910, 14 p., http://dx.doi.org/10.3133/ ds910.

Lema, S.C., J.T. Dickey, I.R. Schultz, P. Swanson. (2009). "Thyroid hormone regulation of mRNAs encoding thyrotropin betasubunit, glycoprotein alpha-subunit, and thyroid hormone receptors alpha and beta in brain, pituitary gland, liver, and gonads of an adult teleost, Pimephales promelas." Journal of Endocrinology 202(1):43-54.

Li, W., J. Zha, P.A. Spear, Z. Wang. (2009). "Changes of thyroid hormone levels and related gene expression in Chinese rare minnow (Gobiocyris rarus) during 3-amino-1,2,4triazole exposure and recovery." Aquatic Toxicology 92:50-57.

Liu, C., Q. Wang, K. Liang, J. Liu, B. Zhou, X. Zhang, H. Liu, J.P. Giesy, H. Yu. (2013). "Effects of tris(1,3-dichloro-2-propyl) phosphate and triphenyl phosphate on receptorassociated mRNA expression in zebrafish embryos/larvae." Aquatic Toxicology 128-129:147-157.

Moccia, R.D., J.F. Leatherland, R.A. Sonstegard. (1981). "Quantitative interlake comparison of thyroid pathology in Great Lakes coho (Oncorynchus kisutch) and chinook (Oncorhynchus tschawytscha) salmon." Cancer Research 41:2200-2210.

Moccia, R.D., G.A. Fox, A. Britton. (1986). "A quantitative assessment of thyroid histopathology of herring gulls (Larus argentatus) from the Great Lakes and a hypothesis on the causal role of environmental contaminants." Journal of Wildlife Disease 22(1):6070 .

Nieves-Puigdoller, K., B.T. Boirnsson, S.D. McCormick. (2007). "Effects of hexazinone and atrazine on the physiology and endocrinology of smolt development in Atlantic salmon." Aquatic Toxicology 84(1):27-37.

Noyes, P.D. and Stapleton, H.M. (2014). "PBDE flame retardants.” Endocrine Disruptors 2(1): e29430, DOI:10.4161/endo.29430.

Orozco, A. and Valverde, R.C. (2005). "Thyroid hormone deiodination in fish." Thyroid 15(8):799-813.

Patino, R., M.R. Wainscott, E.I. Cruz-Li, S. Balakrishnan, C. McMurry, V.S. Blazer, T.A. Anderson. (2003). "Effects of ammonium perchlorate on the reproductive performance and thyroid follicle histology of zebrafish." Environmental Toxicology and Chemistry 22:1115-1121. 
Picard-Aitken, M., H. Fournier, R. Pariseau, D.J. Marcogliese, D.G. Cyr. (2007). “Thyroid disruption in walleye (Sander vitreus) exposed to environmental contaminants: cloning and use of iodothyronine deiodinases as molecular biomarkers." Aquatic Toxicology 83:200-211.

R Core Development Team. (2016). R: a language and environment for statistical computing. $R$ Foundation for Statistical Computing, Vienna, Austria. http://www.R-project.org/.

Rafferty, S.D., V.S. Blazer, A.E. Pinkney, J.L. Grazio, E.C. Obert, L. Boughton. (2009). “A historic perspective on the 'fish tumors or other deformities' beneficial use impairment at Great Lakes areas of concern.” Journal of Great Lakes Research 35:496-506.

Rolland, R. (2000). "A review of chemically-induced alterations in thyroid and vitamin A status from field studies of wildlife and fish." Journal of Wildlife Disease 36:615-635.

Rohr, J.R. and K.A. McCoy. (2010). "A qualitative meta-analysis reveals consistent effects of atrazine on freshwater fish and amphibians." Environmental Health Perspectives 118(1):20-32.

Schnitzler, J. G., E. Koutrakis, U. Siebert, J.P. Thome, K. Das. (2008). "Effects of persistent organic pollutants on the thyroid function of the European sea bass (Dicentrarchus labrax) from the Aegean sea, is it an endocrine disruption?" Marine Pollution Bulletin 56(10):1755-1764.

Shi, X.J., C. Liu, G. Wu, B. Zhou. (2009). "Waterborne exposure to PFOS causes disruption of the hypothalamus-pituitary-thyroid axis in zebrafish larvae." Chemosphere 77:10101018.

Simmons, D.B.D., M.E. McMaster, E.J. Reiner, L.M. Hewitt, J.L. Parrott, B.J. Park, S.B. Brown, J.P. Sherry. (2014). "Wild fish from the Bay of Quinte Area of Concern contain elevated tissue concentrations of PCBs and exhibit evidence of endocrine-related health effects." Environment International 66:124-137.

Smith, I.R., H.W. Ferguson, M.A. Hayes. "Histopathology and prevalence of epidermal papillomas epidemic in brown bullhead, Ictalurus nebulosus (Lesueur), and white sucker, Catostomus commersoni (Lacepede), populations from Ontario, Canada. Journal of Fish Diseases 12(4):373-388.

Sohoni, P., C.R Tyler, K. Hurd, J. Caunter, M. Hetheridge, T. Williams, C. Woods, M. Evans, R. Toy, M. Gargas, J.P. Sumpter. (2001). "Reproductive effects of longterm exposure to bisphenol A in the fathead minnow (Pimephales promelas)." Environmental Science Technology 35:2917e2925.

Stephens, S.M., A.Y.A. Alkindi, C.P. Waring, J.A. Brown. (1997). "Corticosteroid and thyroid responses of larval and juvenile turbot exposed to the water-soluble fractions of crude oil.” Journal of Fish Biology 50:953-964. 
Sun, H.J., P. Xiang, M.H. Tang, L. Sun, L.Q. Ma. (2016). “Arsenic impacted the development, thyroid hormone and gene transcription of thyroid hormone receptors in bighead carp larvae (Hypophthalmichthys nobilis)." Journal of Hazardous Materials 303:76-82.

Teh, S.J., S.M. Adams, D.E. Hinton. (1997). "Histopathologic biomarkers in feral freshwater fish populations exposed to different types of contaminant stress." Aquatic Toxicology 37:5170.

Truter, J.C., J.H. van Wyk, P.J. Oberholster, A.M. Botha, W.J. Luus-Powell. (2016). “The expression of selected genes linked to metabolic homeostasis in obese pansteatitissuffering Mozambique tilapia, Oreochromis mossambicus (Peters). Journal of Fish Disease 39:69-85.

U.S. FDA. (2018). Bioanalytical Method Validation Guidance for Industry. U.S. Department of Health and Human Services, Food and Drug Administration, Center for Drug Evaluation and Research. https://www.fda.gov/downloads/drugs/guidances/ucm070107.Pdf

Vandenberg, L.N., T. Colborn, T.B. Hayes, J.J. Heindel, D.R. Jacobs, D.H. Lee, T. Shoida, A.M. Soto, F.S. Von Saal, W.V. Welshons, R.T. Zoeller, J.P. Myers. (2012). "Hormones and endocrine-disrupting chemicals: low-dose effects and nonmonotonic dose responses. Endocrinology Reviews 33:378-455.

Wu, R.S., C.A. Pollino, D.W. Au, G.J. Zheng, B.B. Yuen, P.K. Lam. (2003). "Evaluation of biomarkers of exposure and effect in juvenile areolated grouper (Epinephelus areolatus) on foodborne exposure to benzo[a]pyrene." Environmental Toxicology and Chemistry 22(7):1568-73

Yu, L. J. Deng, X. Shi, C. Liu, K. Yu, B. Zhou. (2010). "Exposure to DE-71 alters thyroid hormone levels and gene transcription in the hypothalamic-pituitary-thyroid axis of zebrafish larvae." Aquatic Toxicology 97:226-233. 


\section{Tables}

Table 1. Sites with available histological data.

\begin{tabular}{|l|l|l|l|}
\hline Brown bullhead & Site & Season & $n$ \\
\hline Detroit River & Trenton Channel & Spring & 17 \\
\hline Rochester Embayment & Irondequoit Bay & Spring & 14 \\
\cline { 2 - 4 } & Long Pond & Spring & 7 \\
\hline Smallmouth Bass & Site & Season & $n$ \\
\hline AOC & Green Bay & Spring & 17 \\
\hline River Raisin & Upper Estuary & Spring & 8 \\
\hline Fox River & Middle Estuary & Fall & 17 \\
\hline St. Louis River & Fall & 13 \\
\hline
\end{tabular}


Table 2. Genes of interest.

\section{Thyroid Gene Name}

Thyroid Hormone Receptor $\alpha(\mathrm{THR} \alpha)$

Thyroid Hormone Receptor $\beta$ (THR $\beta$ )

Type I Deiodinase (DIO1)*

Type II Deiodinase (DIO2)*

Housekeeping Gene Name

Elongation Factor $1 \alpha$

Eukaryotic Translation Initiation Factor 3D

Hypoxanthine Phosphoribosyltransferase 1

RNA binding motif protein Xlinked 2

Ribosomal Protein L8

Phosphoenolpyruvate Carboxykinase*

Tata Box Binding Protein*

* Data unavailable for brown bullhead 
Table 3. Recovery in pg/mL of known amounts of triiodothyronine (T3) and thyroxine (T4) in charcoal stripped brown bullhead (BBH) and smallmouth bass (SMB) plasma $(\mathrm{OOR}<$, below the range of detection; OOR>, above the range of detection).

\begin{tabular}{|l|l|l|l|}
\hline Analyte & Added & Recovered - BBH & Recovered - SMB \\
\hline T3 & 0 (Blank) & OOR $<$ & OOR< \\
\cline { 2 - 4 } & 312.5 & 320.21 & 453.85 \\
\cline { 2 - 4 } & 5,000 & 6179.41 & 5861.71 \\
\hline \multirow{3}{*}{ 4 } & 0 (Blank) & 6816.14 & 7867.3 \\
\cline { 2 - 4 } & 3,125 & 25,318 & 25,520 \\
\cline { 2 - 4 } & 100,000 & OOR $>$ & OOR $>$ \\
\hline
\end{tabular}


Table 4. Mean measured values $(\mathrm{pg} / \mathrm{mL})$ by duplicate analysis of treated plasma spiked with $5000 \mathrm{pg} / \mathrm{mL}$ triiodothyronine (T3) and 100,000 pg/mL thyroxine (T4) at three levels of dilution. Measured values compared to theoretical values show that the extraction of hormones was not complete at the same dose levels (OOR>, above the range of detection).

\begin{tabular}{|l|l|l|l|l|}
\hline Analyte & Theoretical value & Dilution & $\begin{array}{l}\text { Measured } \\
\text { values }\end{array}$ & $\begin{array}{l}\text { Percentage } \\
\text { difference }\end{array}$ \\
\hline \multirow{2}{*}{ T3 } & \multirow{2}{*}{5,000} & $1: 6$ & 6035.64 & $21 \%$ \\
\cline { 3 - 5 } & & $1: 10$ & 6234.37 & $25 \%$ \\
\cline { 3 - 5 } & \multirow{2}{*}{$\mathrm{T} 4$} & $1: 12$ & 7137.01 & $43 \%$ \\
\cline { 3 - 5 } & & $1: 6$ & OOR $>$ & - \\
\cline { 3 - 5 } & & $1: 10$ & OOR $>$ & - \\
\cline { 2 - 5 } & $1: 12$ & OOR $>$ & - \\
\hline
\end{tabular}


Table 5. Recovery in $\mu \mathrm{IU} / \mathrm{mL}$ of known amounts of thyroid stimulating hormone (TSH) in charcoal stripped brown bullhead (BBH) and smallmouth bass (SMB) plasma.

\begin{tabular}{|l|l|l|l|}
\hline Analyte & Added & Recovered - BBH & Recovered - SMB \\
\hline \multirow{5}{*}{ TSH } & 0 & 3.612 & 3.562 \\
\cline { 2 - 4 } & 2.5 & 4.360 & 3.900 \\
\cline { 2 - 4 } & 5 & 5.637 & 4.342 \\
\cline { 2 - 4 } & 10 & 8.329 & 5.401 \\
\cline { 2 - 4 } & 20 & 13.155 & 9.724 \\
\hline
\end{tabular}


Table 6. Results of Pearson correlation analysis for the investigated variables in smallmouth bass $(\mathrm{n}=55) . *: \mathrm{p} \leq 0.05, * *: \mathrm{p}<0.01$.

\begin{tabular}{|c|c|c|c|c|c|c|c|c|c|c|c|}
\hline Parameters & $\mathrm{TECH}^{1}$ & $\begin{array}{c}\text { Percent } \\
\text { Vacuolation }\end{array}$ & $\begin{array}{l}\text { TECA: } \\
\text { Colloid }^{2}\end{array}$ & $\mathrm{TSH}^{3}$ & $\mathrm{~T} 3^{4}$ & $\mathrm{~T} 4^{5}$ & $\mathrm{~T} 3^{4} / \mathrm{T} 4^{5}$ & $\mathrm{THR} \alpha^{6}$ & THR $\beta^{7}$ & $\mathrm{DIO}^{8}$ & $\mathrm{DIO}^{9}$ \\
\hline $\mathrm{TECH}^{1}$ & 1 & $0.54 * *$ & $0.67 * *$ & -0.22 & $\begin{array}{l}-0.01 \\
\end{array}$ & -0.01 & -0.03 & 0.24 & 0.22 & 0.23 & 0.11 \\
\hline $\begin{array}{l}\text { Percent } \\
\text { Vacuolation }\end{array}$ & $0.54 * *$ & 1 & $0.45 * *$ & -0.11 & -0.01 & 0.08 & -0.13 & 0.03 & 0.10 & 0.12 & 0.15 \\
\hline TECA:colloid ${ }^{2}$ & $0.67 * *$ & $0.45 * *$ & 1 & $-0.30 *$ & $-0.33 *$ & 0.16 & $-0.28 *$ & $0.37 * *$ & 0.23 & 0.16 & -0.14 \\
\hline $\mathrm{TSH}^{3}$ & -0.22 & -0.11 & $-0.30 *$ & 1 & $0.51^{* *}$ & -0.16 & $0.44 * *$ & 0.44 & -0.25 & -0.12 & $0.30 *$ \\
\hline $\mathrm{T} 3^{4}$ & -0.01 & -0.01 & $-0.33 *$ & 0.51 ** & 1 & -0.17 & $0.74 * *$ & $-0.47 * *$ & -0.12 & -0.21 & $0.53 * *$ \\
\hline $\mathrm{T} 4^{5}$ & -0.01 & 0.08 & 0.16 & -0.16 & -0.17 & 1 & $-0.70^{* *}$ & -0.05 & 0.11 & 0.22 & -0.11 \\
\hline $\mathrm{T} 3^{4} / \mathrm{T}^{5}$ & -0.03 & -0.13 & $-0.28 *$ & $0.44 * *$ & $0.74^{* *}$ & $-0.70^{* *}$ & 1 & $-0.32 * *$ & -0.20 & $-0.28 *$ & $0.43 * *$ \\
\hline $\mathrm{THR} \alpha^{6}$ & 0.24 & 0.03 & $0.37 * *$ & -0.25 & $-0.47 * *$ & -0.05 & $-0.32 * *$ & 1 & 0.24 & 0.23 & -0.19 \\
\hline $\operatorname{THR}^{7}$ & 0.22 & 0.10 & 0.23 & -0.12 & -0.12 & 0.11 & -0.20 & 0.24 & 1 & -0.06 & 0.07 \\
\hline $\mathrm{DIO}^{8}$ & 0.23 & 0.12 & 0.16 & 0 & -0.21 & 0.22 & $-0.28 *$ & 0.23 & -0.06 & 1 & 0.05 \\
\hline $\mathrm{DIO} 2^{9}$ & 0.11 & 0.15 & -0.14 & 0.30* & $0.53^{* *}$ & -0.11 & $0.43^{* *}$ & -0.19 & 0.07 & 0.05 & 1 \\
\hline $\begin{array}{l}{ }^{1} \text { Thyr } \\
{ }^{2} \text { Ratio } \\
{ }^{3} \text { Thyr } \\
{ }^{4} \text { Triio } \\
{ }^{5} \text { Thyr } \\
{ }^{6} \text { Thyr } \\
{ }^{7} \text { Thyr } \\
{ }^{8} \text { Deio }\end{array}$ & $\begin{array}{l}\text { ithelial c } \\
\text { yroid ep } \\
\text { Imulating } \\
\text { ronine } \\
\text { ceptor al } \\
\text { ceptor be } \\
\text { I }\end{array}$ & $\begin{array}{l}\text { height } \\
\text { lial cell area } \\
\text { rmone }\end{array}$ & lloid are & & & & & & & & \\
\hline
\end{tabular}


${ }^{9}$ Deiodinase II

Table 7. Results of Pearson correlation analysis for the investigated variables in brown bullhead $(\mathrm{n}=38)$. $^{*}: \mathrm{p} \leq 0.05$, **: $\mathrm{p}<0.01$.

\begin{tabular}{|c|c|c|c|c|c|c|c|c|c|}
\hline Parameters & $\mathrm{TECH}^{1}$ & $\begin{array}{c}\text { Percent } \\
\text { Vacuolation }\end{array}$ & $\begin{array}{l}\text { TECA: } \\
\text { Colloid }^{2}\end{array}$ & $\mathrm{TSH}^{3}$ & $\mathrm{~T}^{4}$ & $\mathrm{~T} 4^{5}$ & $\mathrm{~T} 3^{4} / \mathrm{T} 4^{5}$ & $\mathrm{THR} \alpha^{6}$ & $\operatorname{THR} \beta^{7}$ \\
\hline $\mathrm{TECH}^{1}$ & 1 & 0.27 & $0.57 * *$ & 0.19 & 0.19 & 0.15 & 0.11 & -0.01 & -0.11 \\
\hline $\begin{array}{l}\text { Percent } \\
\text { Vacuolation }\end{array}$ & 0.27 & 1 & $0.35 *$ & 0.14 & 0.08 & 0.02 & 0.01 & 0.12 & 0.28 \\
\hline TECA:colloid ${ }^{2}$ & $0.57 * *$ & $0.35 *$ & 1 & 0.23 & 0.23 & 0.14 & 0.09 & 0.15 & -0.18 \\
\hline $\mathrm{TSH}^{3}$ & 0.19 & 0.14 & 0.23 & 1 & $0.77 * *$ & -0.12 & $0.74 * *$ & 0.25 & 0 \\
\hline $\mathrm{T}^{4}$ & 0.19 & 0.08 & 0.23 & $0.77 * *$ & 1 & 0.04 & $0.87 * *$ & 0.30 & -0.17 \\
\hline $\mathrm{T} 4^{5}$ & 0.15 & 0.02 & 0.14 & -0.12 & 0.04 & 1 & $-0.40 * *$ & 0.12 & -0.13 \\
\hline $\mathrm{T} 3^{4} / \mathrm{T} 4^{5}$ & 0.11 & 0.01 & 0.09 & $0.74 * *$ & $0.87 * *$ & $-0.40 * *$ & 1 & 0.19 & -0.07 \\
\hline THR $\alpha^{6}$ & -0.01 & 0.12 & 0.15 & 0.25 & 0.30 & 0.12 & 0.19 & 1 & 0.11 \\
\hline THR $\beta^{7}$ & -0.11 & 0.28 & -0.18 & 0 & -0.17 & -0.13 & -0.07 & 0.11 & 1 \\
\hline $\begin{array}{l}{ }^{1} \text { Thyroid epithelia } \\
{ }^{2} \text { Ratio of thyroid } \\
{ }^{3} \text { Thyroid stimulat } \\
{ }^{4} \text { Triiodothyronine } \\
{ }^{5} \text { Thyroxine } \\
{ }^{6} \text { Thyroid receptor } \\
{ }^{7} \text { Thyroid receptor }\end{array}$ & $\begin{array}{l}1 \text { height } \\
\text { elial cell } \\
\text { lormone }\end{array}$ & colloid area & & & & & & & \\
\hline
\end{tabular}


Table 8. Detected concentrations of chemicals in $\mu \mathrm{g} / \mathrm{L}$ summarized from Lee et al. $2012^{1}$ (<, less than; E, estimated concentration; b, value extrapolated below the lowest calibration standard, method range, or instrument linear range and data have unknown bias; $\mathrm{n}$, value is below the reporting level but at or above the detection level).

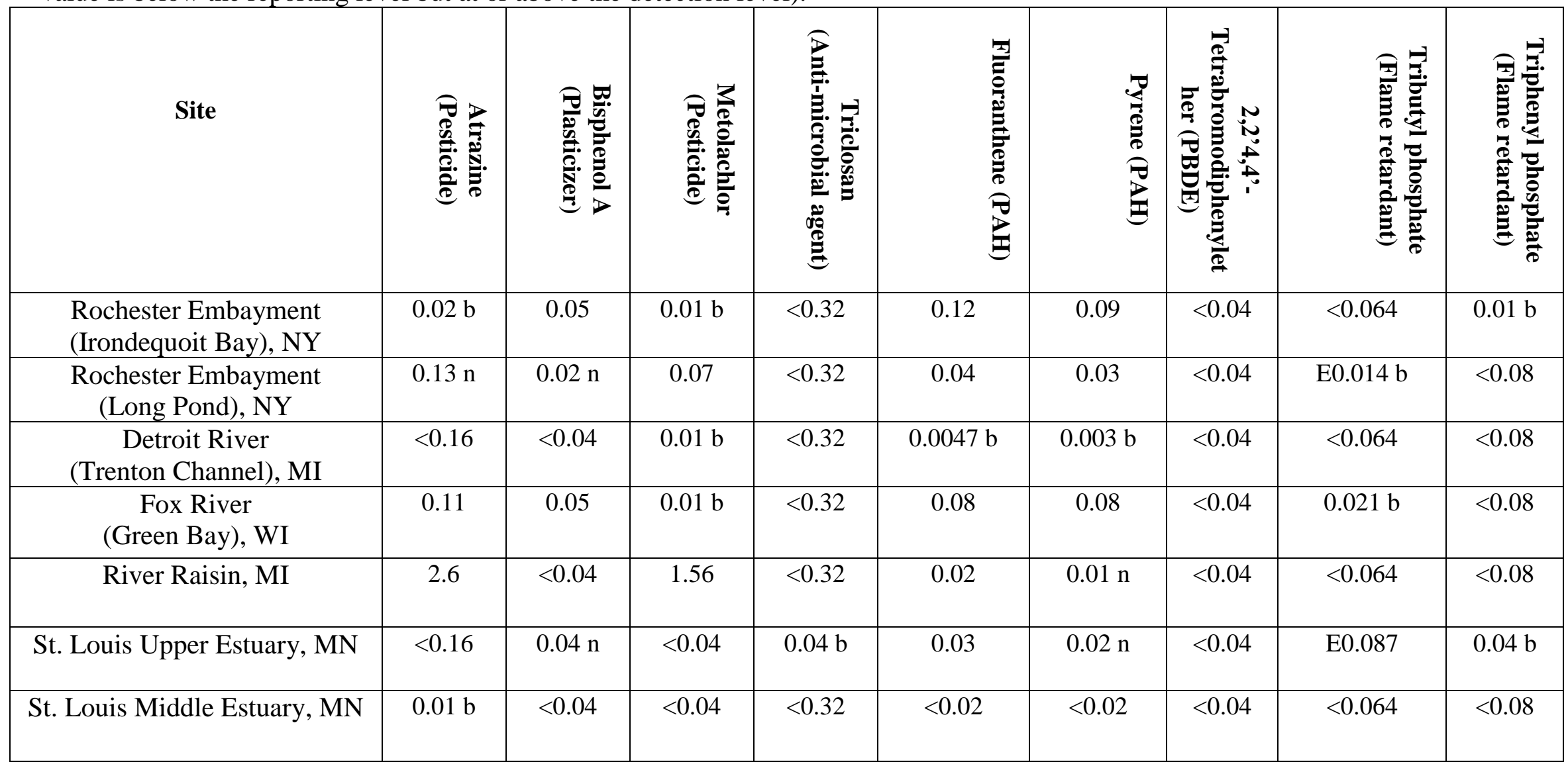

${ }^{1}$ Lee, K.E., S.K. Langer, M.A. Menheer, D. Gefell. (2015). "Chemicals of emerging concern in water and bottom sediment in Great Lakes Basin, 2012 - Collection methods, analytical, methods, quality assurance, and study data.” U.S. Geological Survey Data Series 910, 14 p., http://dx.doi.org/10.3133/ ds910. 


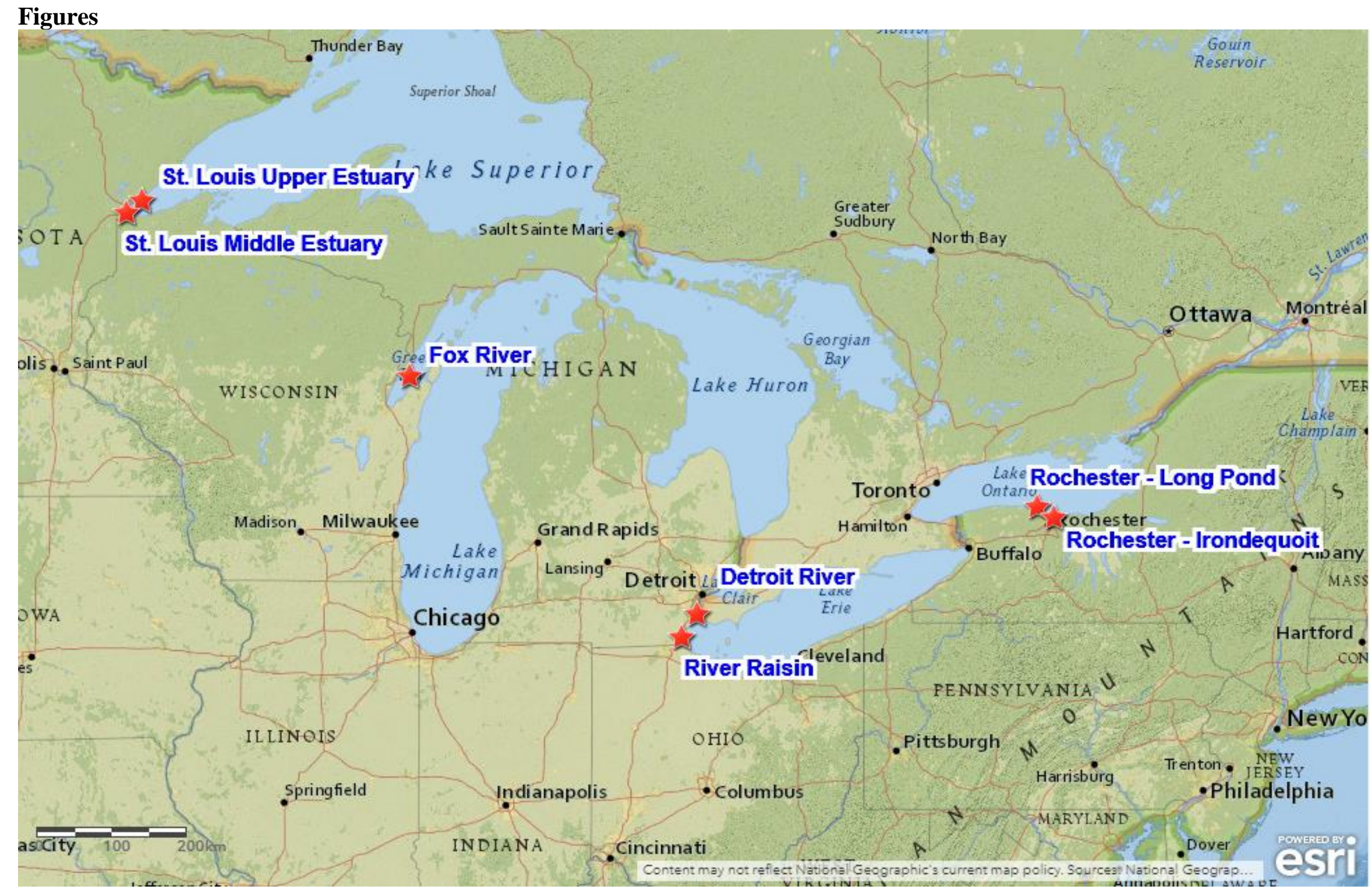

Figure 1. Map of study sites in the Great Lakes basin. Sites were located in Lake Michigan (Fox River), Lake Erie (Detroit River, River Raisin), Lake Ontario (Rochester Embayment: Long Pond, Irondequoit), and Lake Superior (St. Louis Upper Estuary, St. Louis Middle Estuary). 


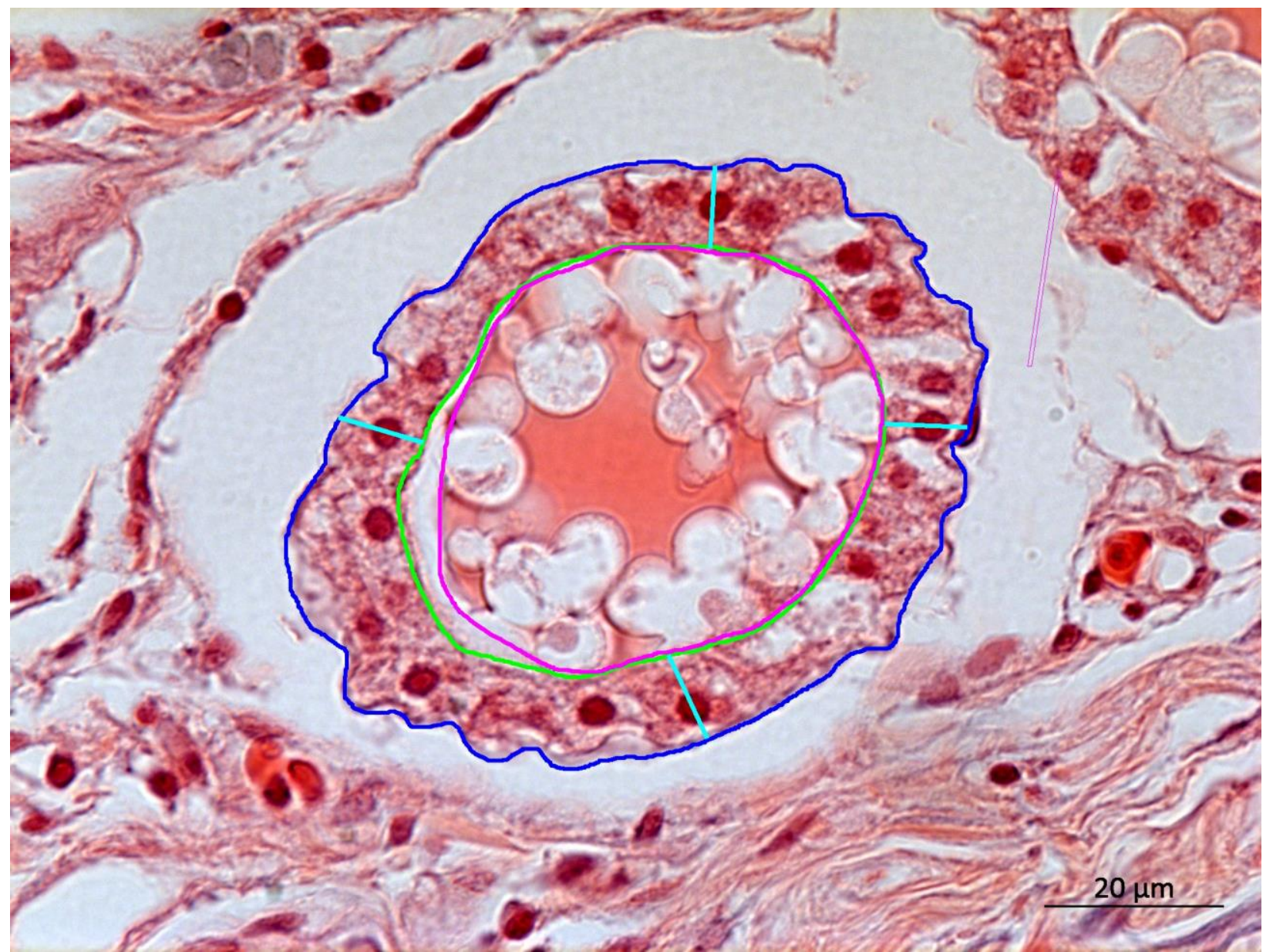

Figure 2. Four thyroid epithelial cell heights (TECH) of each follicle were measured using opposite horizontal and vertical extremes from the basement membrane to the surface adjacent to the colloid (light blue). The dark blue line outlines the area of the follicle and the green line outlines the area of the lumen. Thyroid epithelial cell area (TECA) was calculated by subtracting the area of the lumen from the area of the follicle. A similar approach was taken for the area of the colloid, where the pink line outlines the area of the colloid. Total colloid was calculated by subtracting the area of the droplets from the area of the colloid. 


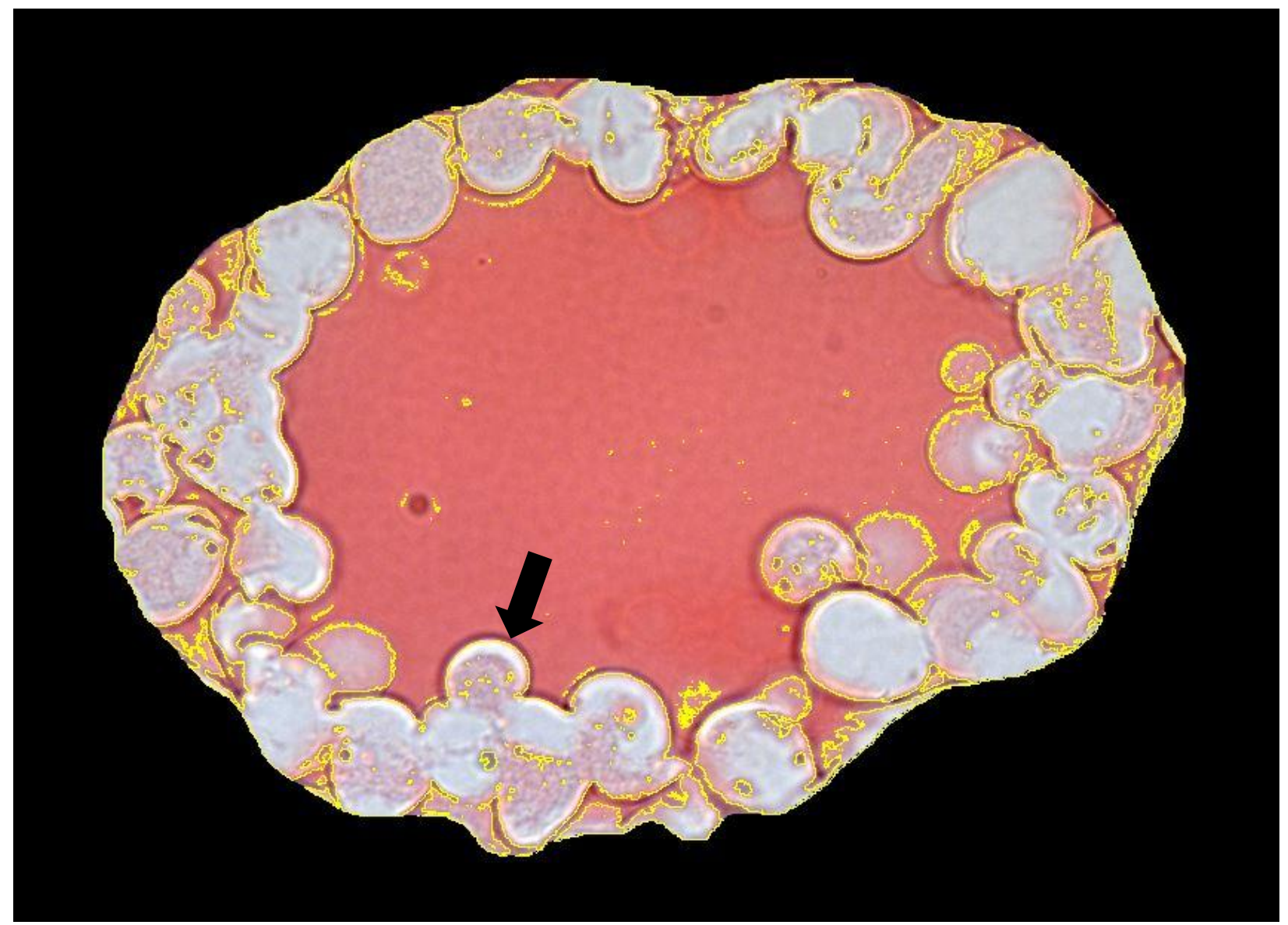

Figure 3. Percent colloid vacuolation was measured isolating the area of the colloid (pink) and subtracting the area of the vacuoles (white). 


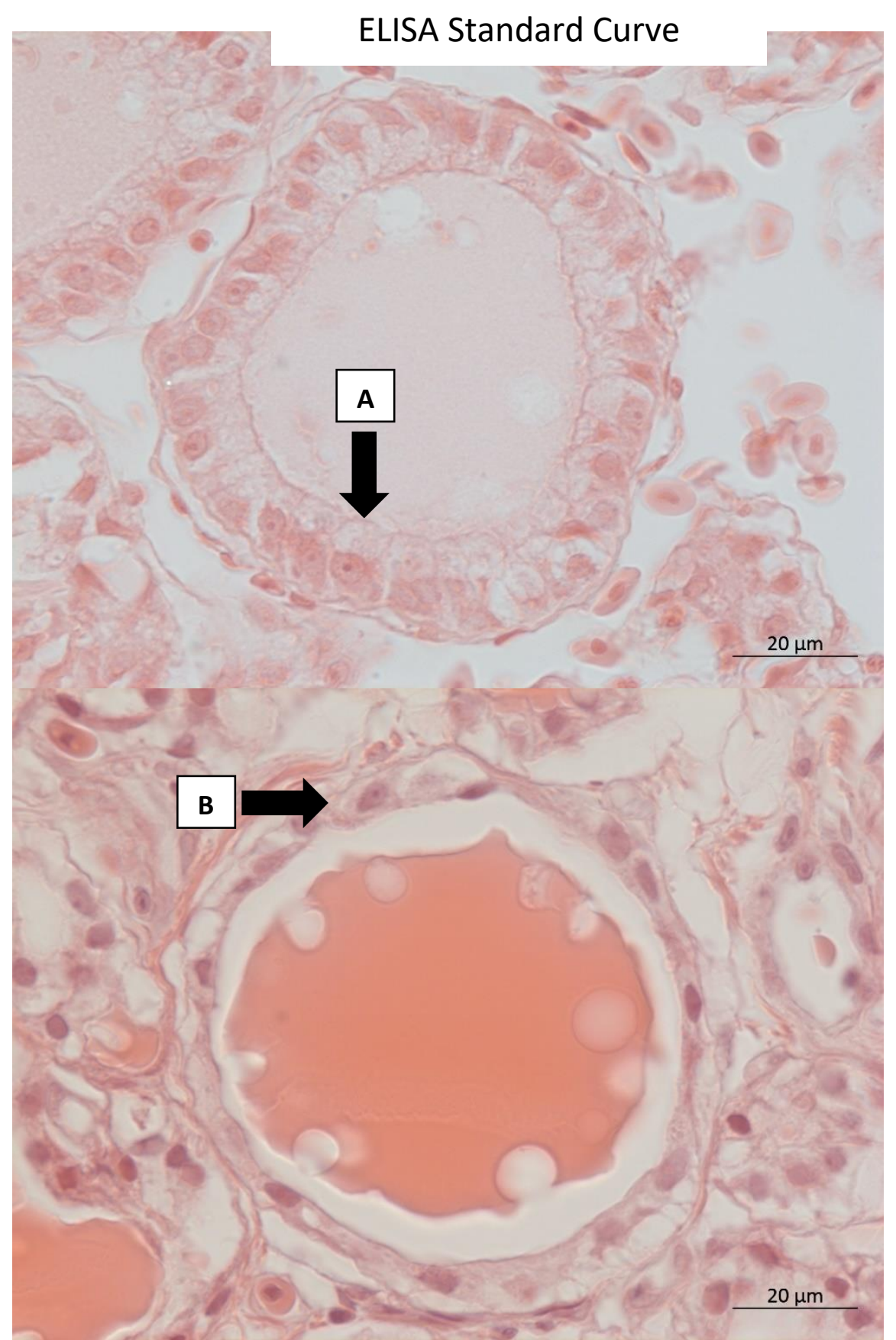

Figure 4. Hypertrophied epithelial cells (A) marked by the appearance of cellular "swelling" in a $\mathrm{BBH}$ thyroid follicle compared to a $\mathrm{BBH}$ follicle with normal epithelial cells (B). 


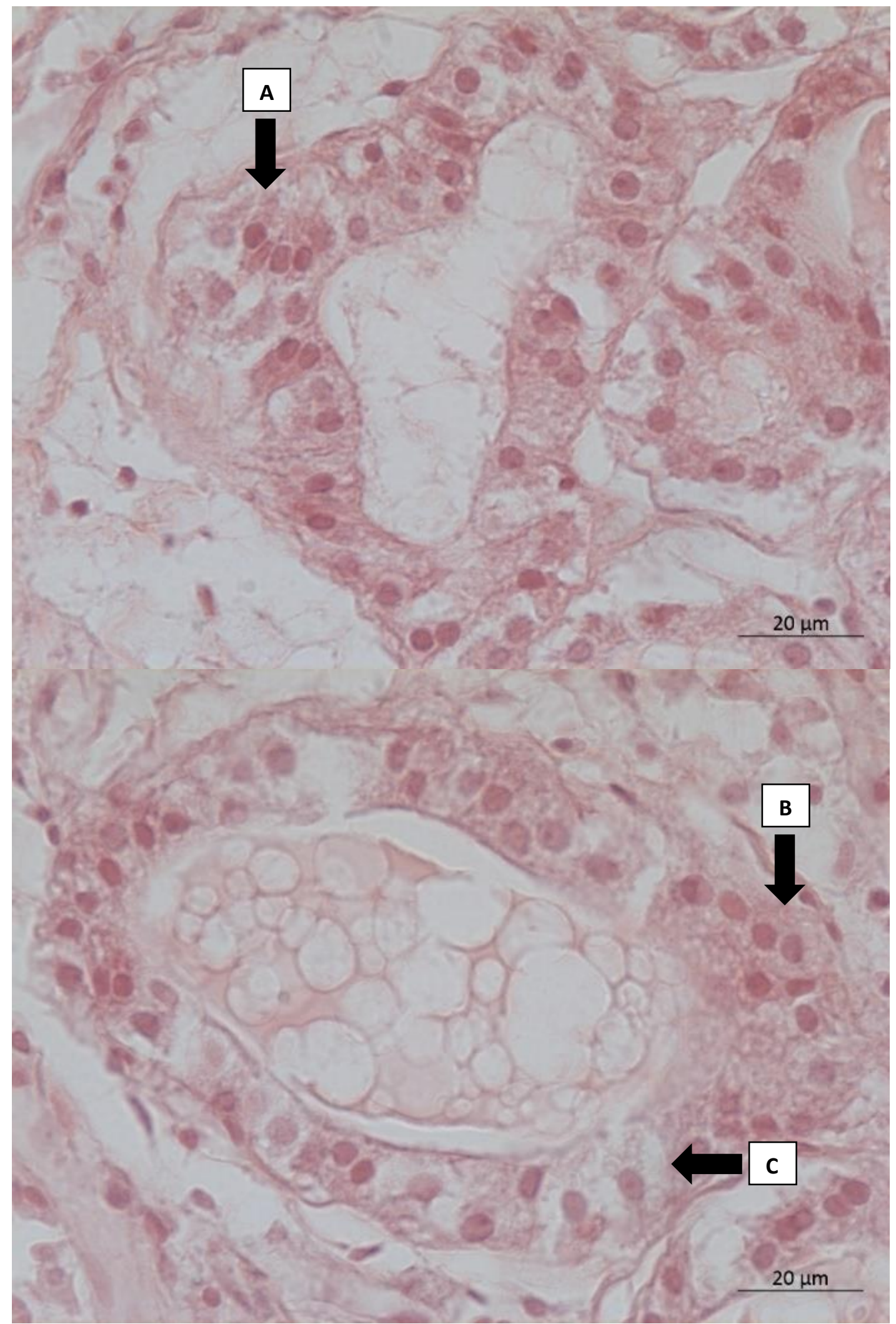

Figure 5. Follicular cell hyperplasia in $\mathrm{BBH}$ follicles demonstrated by stratification of the follicular cells (A and B), with cell hypertrophy (C). 


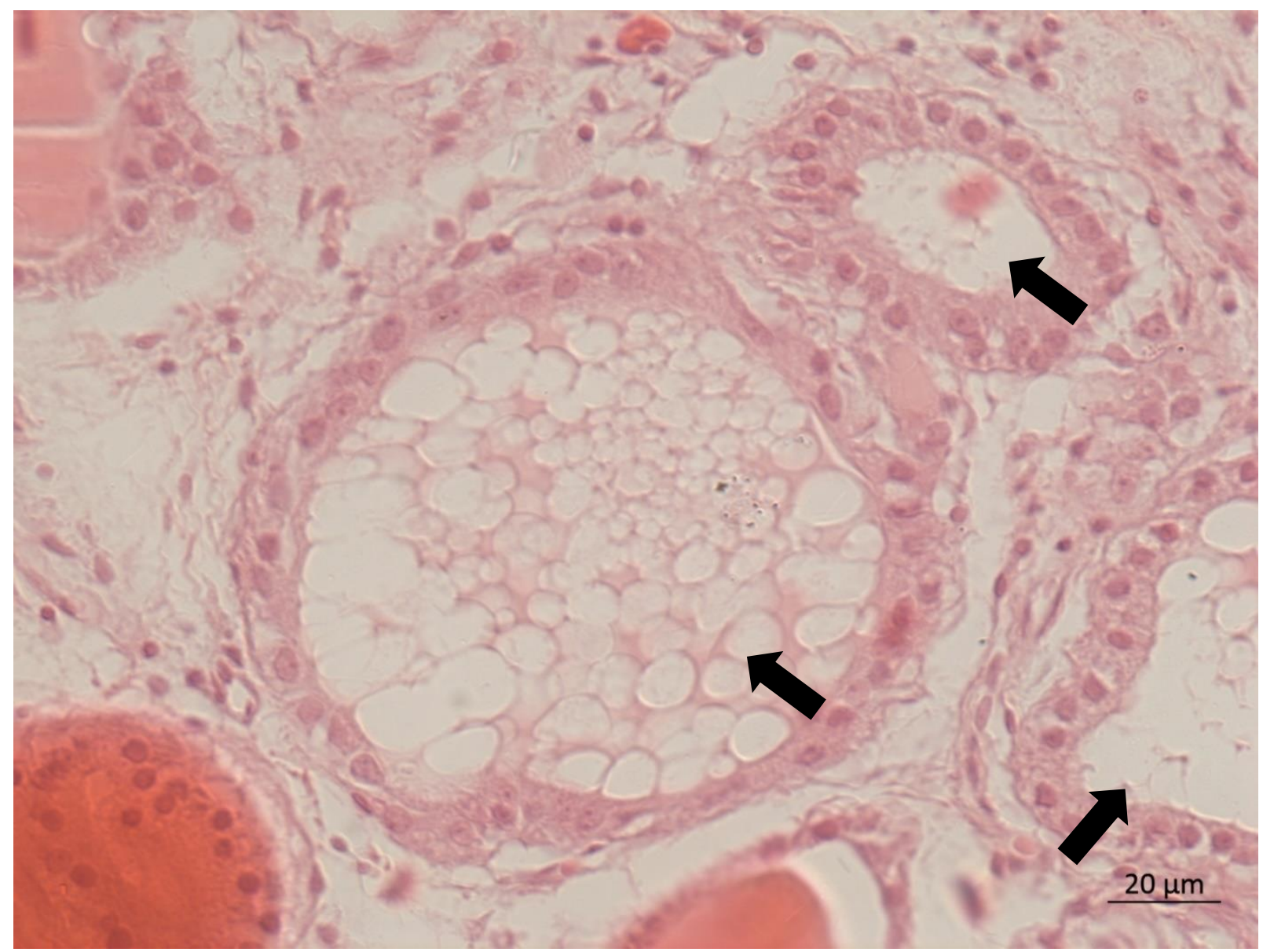

Figure 6. Severe luminal colloid vacuolation in $\mathrm{BBH}$ follicles. 


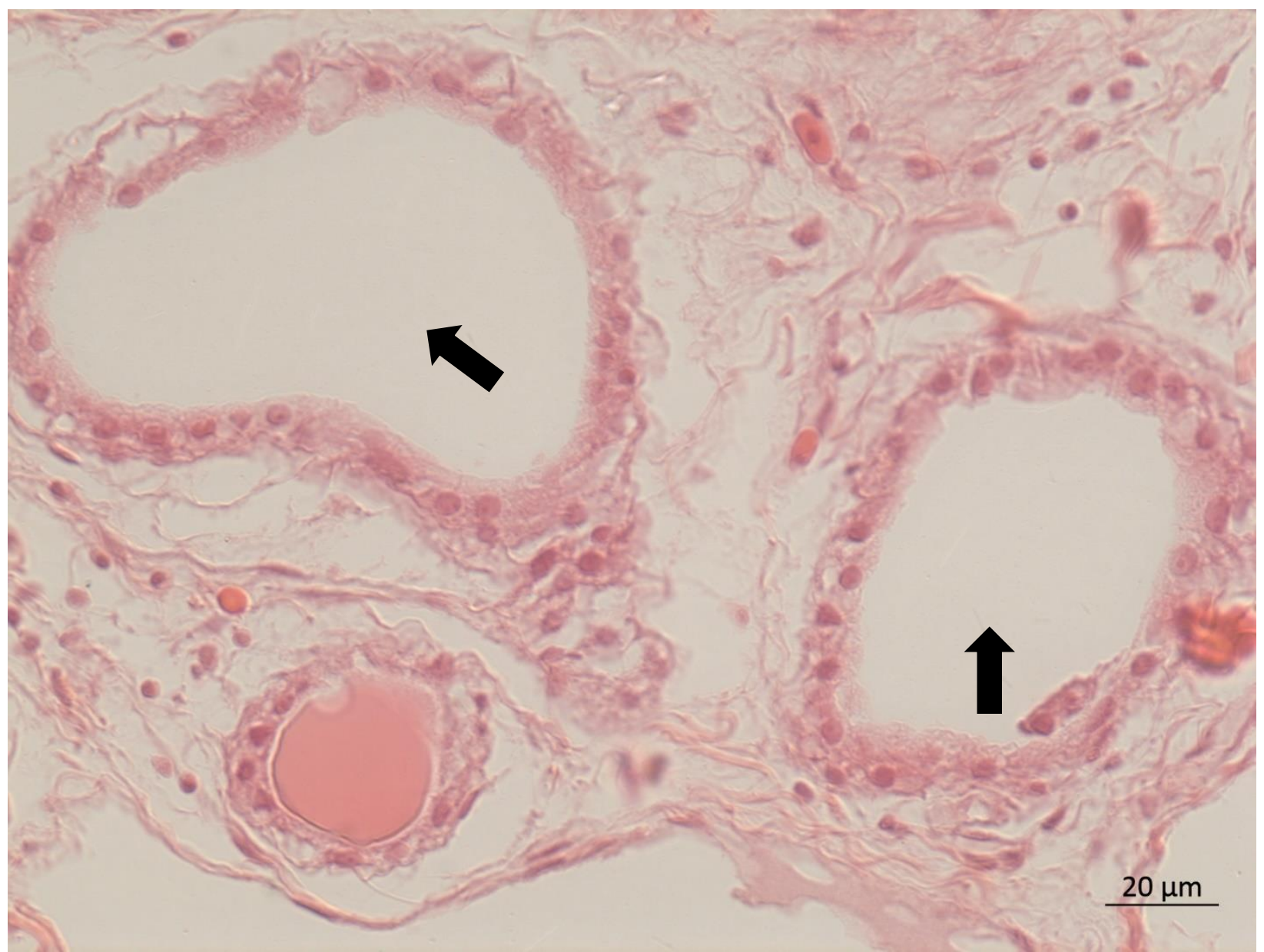

Figure 7. Large BBH follicles devoid of colloid. 


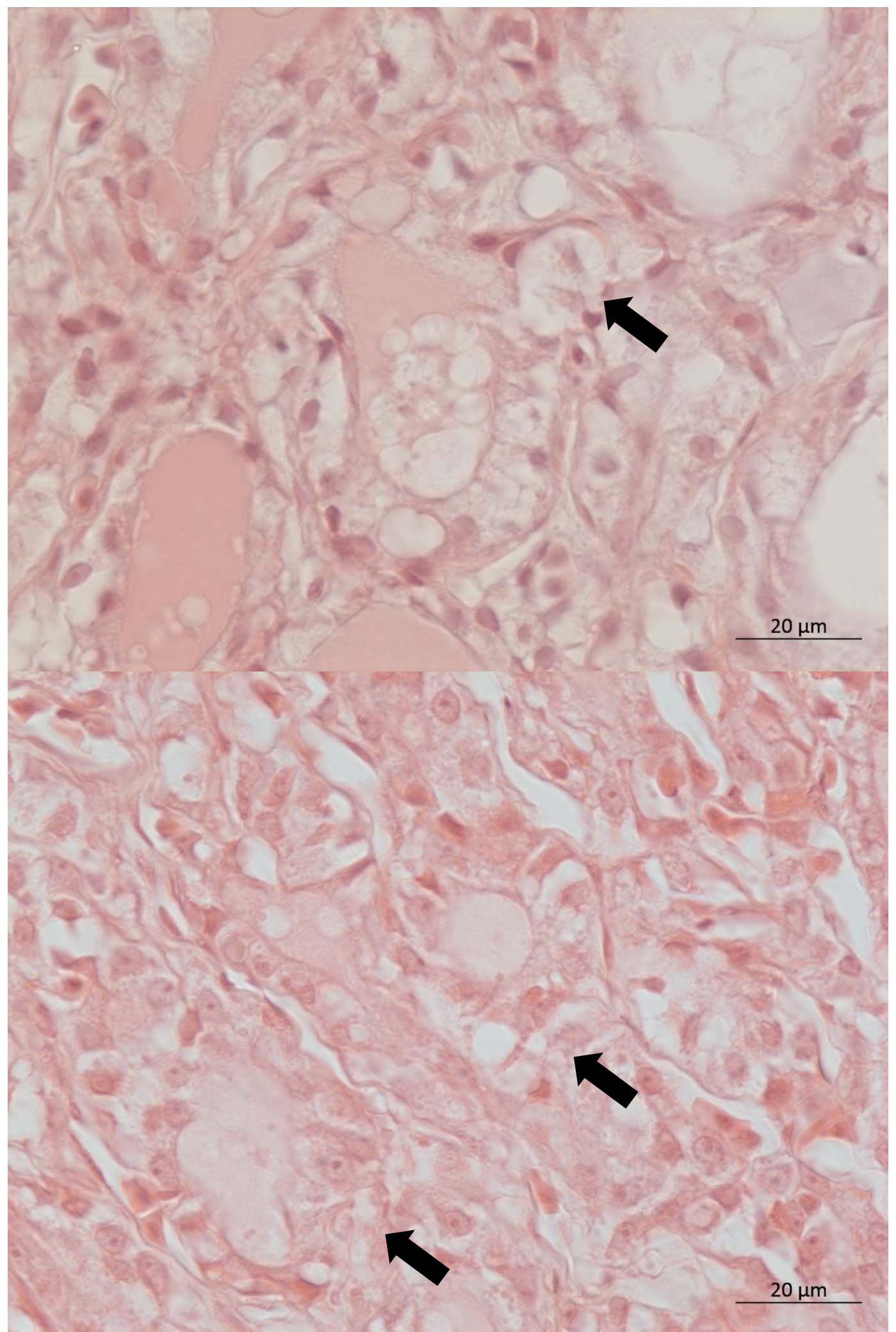

Figure 8. Small, irregular thyroid follicles of SMB sampled in the spring at Fox River. The epithelium lacks structure and is difficult to define. 


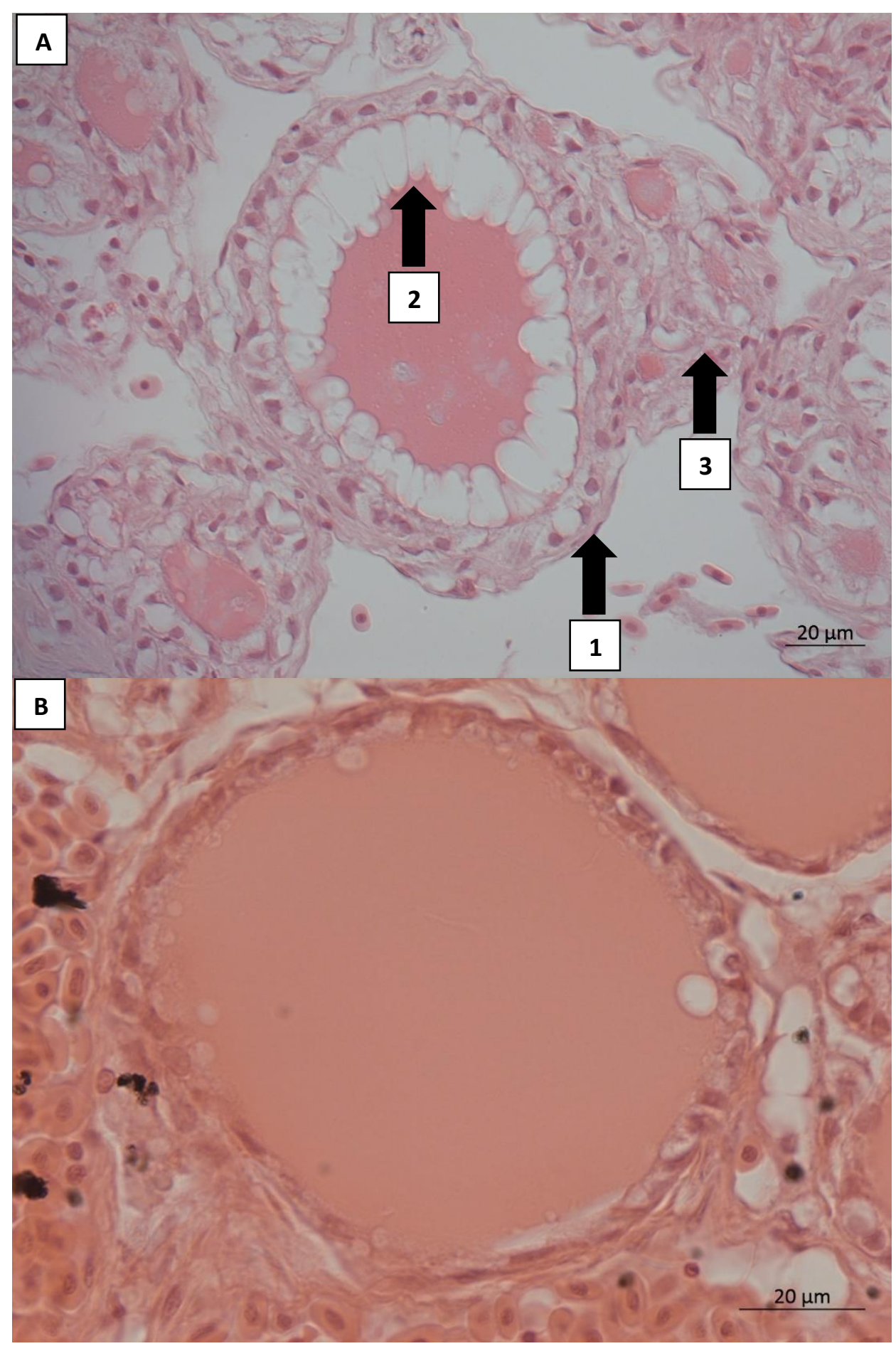

Figure 9. A. Thyroid follicles of SMB during the spring season showing (1) increased height of the epithelial layer, (2) extensive vacuolation, and (3) abnormal stratification. B. Thyroid follicle of SMB during the fall season showing a thin epithelium, a relatively homogenous colloid stock, and very few resorption vacuoles. 

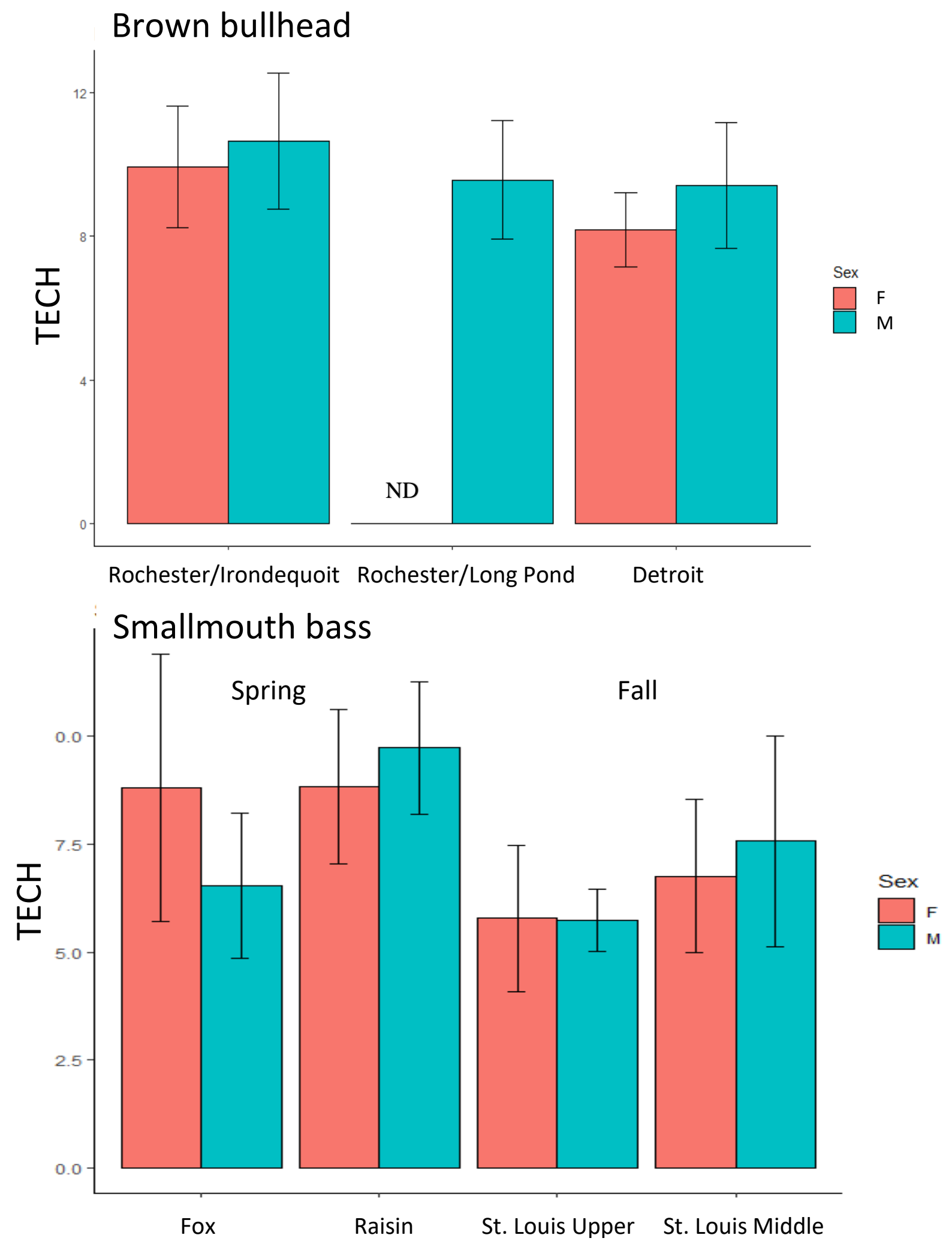

Figure 10. Thyroid epithelial cell height (mean \pm standard deviation) of brown bullhead and smallmouth bass for each site. In SMB, Fox River and River Raisin were sampled in the spring, whereas St. Louis Upper Estuary and St. Louis Middle Estuary were sampled in the fall. ND denotes "No Data." 

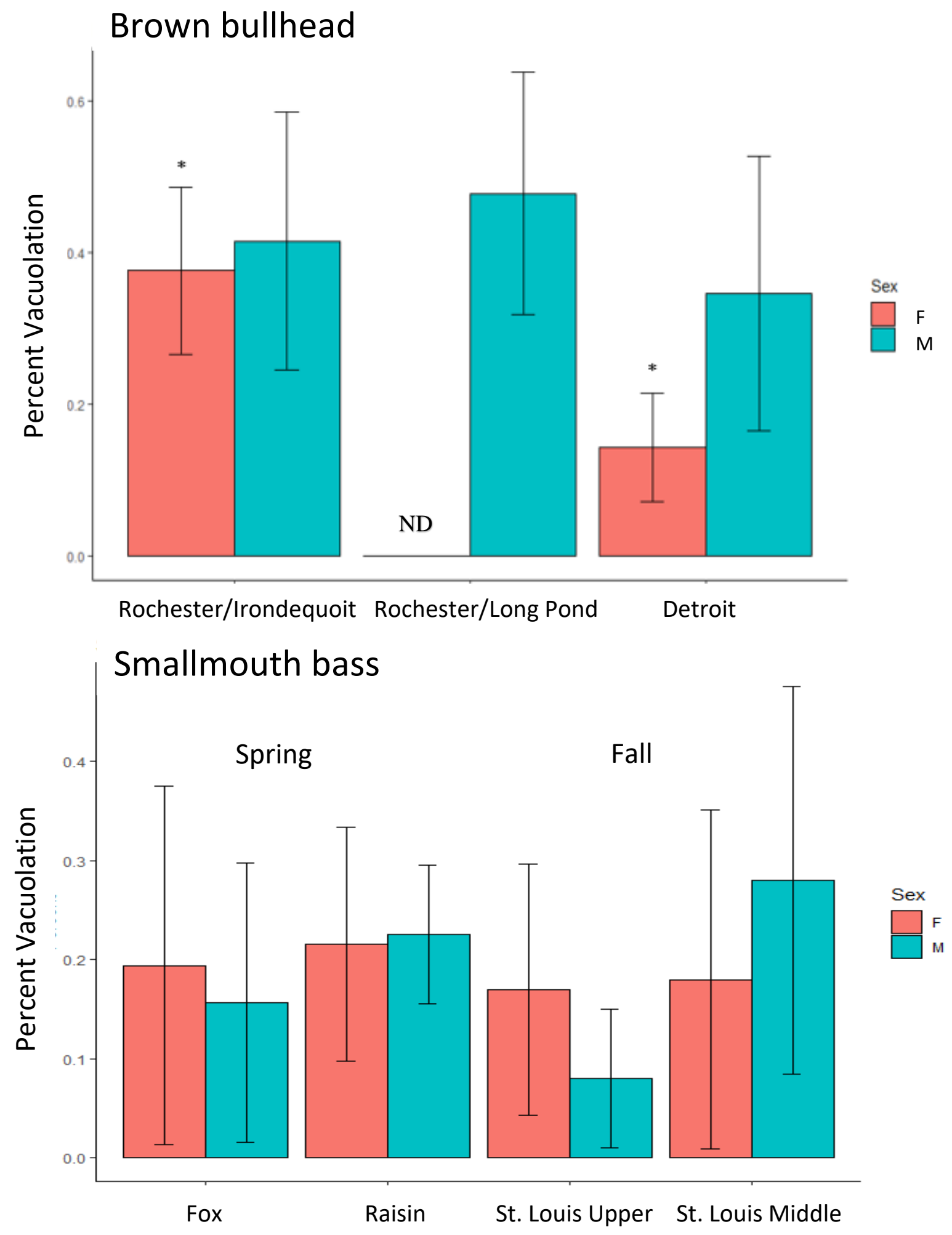

Figure 11. Percent colloid vacuolation (mean \pm standard deviation) in brown bullhead and smallmouth bass. ND denotes "No Data." Asterisk (*) denotes a significant difference. 


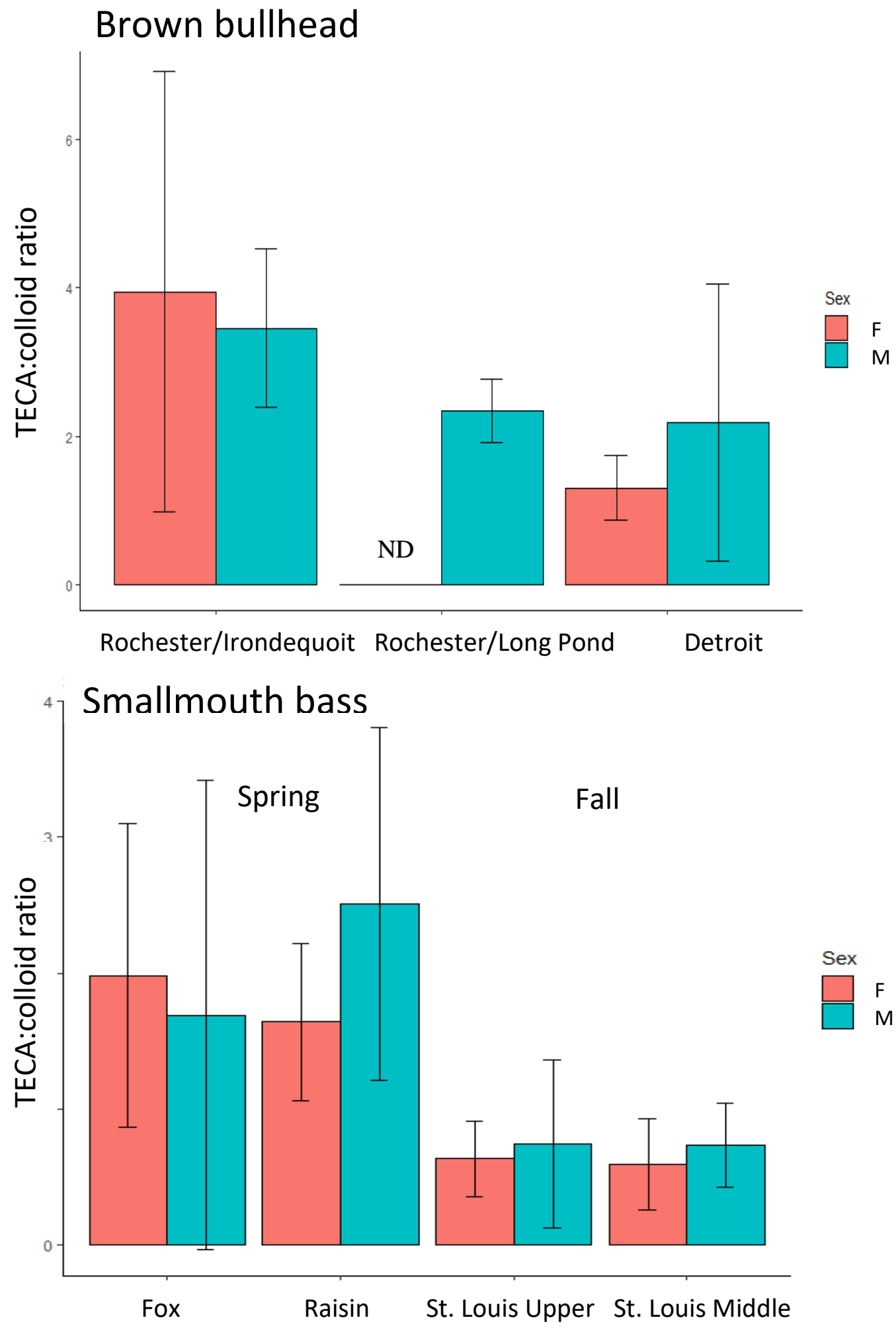

Figure 12. Thyroid epithelial cell area (TECA): colloid area ratio (mean \pm standard deviation) in brown bullhead (Ameiurus nebulosus) from the Rochester Embayment (Irondequoit and Long Pond), and Detroit River, and smallmouth bass (Micropterus dolomieu) from Fox River, River Raisin, St. Louis Upper Estuary, and St. Louis Middle Estuary. ND denotes "No Data." 


\section{Appendix A - Charcoal Stripping Protocol}

Double charcoal-stripped plasma was prepared by adding $50 \mathrm{mg}$ of activated charcoal to each $\mathrm{mL}$ aliquot of plasma, vortexing $10 \mathrm{x}$ for 1 second, and stirring for 1 hour at $20^{\circ} \mathrm{C}$. The mixture was allowed to incubate overnight at $4^{\circ} \mathrm{C}$. The solution was then centrifuged at $4000 \mathrm{xg}$ for 45 minutes at $4^{\circ} \mathrm{C}$, and the supernatant (plasma) was filtered first though a $0.22-\mu \mathrm{m}$ and then through a $0.45-\mu \mathrm{m}$ filter. This process was repeated to ultimately prepare double charcoalstripped plasma. 


\section{Appendix B - Raw Data}

In this appendix, the raw data sheets for histologic, hormone, and gene expression data are contained.

\section{Smallmouth Bass}

\begin{tabular}{|c|c|c|c|c|c|c|c|c|c|c|c|c|c|c|c|}
\hline Location & Season & Fish_ID & Age & Sex & TECH & Percent & TECA_colloid & TSH & T3 & T4 & TH_Ratio & THR $\alpha$ & THR $\beta$ & DIO1 & DIO2 \\
\hline River Raisin & Spring & GL18-01 & & $M$ & 11.99 & 0.277 & 3.82 & 7.151 & 11529.54 & 55087.54 & 0.209294879 & 15.48 & 798.23 & 16.57 & 186.4 \\
\hline River Raisin & Spring & GL18-02 & & $\mathrm{F}$ & 9.46 & 0.301 & 1.50 & 7.178 & 11542.72 & 122864.44 & 0.093946792 & 13.67 & 466.87 & 96.07 & 193.92 \\
\hline River Raisin & Spring & GL18-03 & & M & 9.04 & 0.248 & 2.43 & 7.759 & 10435.74 & 104644.89 & 0.099725271 & 11.32 & 868.33 & 15.08 & 278.59 \\
\hline River Raisin & Spring & GL18-04 & & $\mathrm{F}$ & 7.54 & 0.052 & 2.01 & 6.856 & 8515.29 & 168741.31 & 0.050463576 & 18.02 & 296.16 & 129.28 & 285.04 \\
\hline River Raisin & Spring & GL18-05 & & $\mathrm{F}$ & 10.15 & 0.387 & 2.40 & 5.219 & 11680.01 & 60352.24 & 0.193530679 & 28.79 & 172.25 & 34.1 & 140.37 \\
\hline River Raisin & Spring & GL18-07 & & $\mathrm{F}$ & 7.59 & 0.309 & 1.61 & 5.558 & 10635.87 & 65618.16 & 0.162087294 & 11.62 & 213.53 & 48.33 & 194.16 \\
\hline River Raisin & Spring & GL18-08 & & $\mathrm{F}$ & 9.89 & 0.201 & 2.66 & 6.804 & 11015.13 & 182944.55 & 0.060210211 & 3.97 & 228.24 & 81.4 & 209.55 \\
\hline River Raisin & Spring & GL18-09 & 8 & $\mathrm{~F}$ & 6.99 & 0.127 & 0.97 & 4.944 & 5894.93 & 65775.42 & 0.089622081 & 22.34 & 440.06 & 190.55 & 224.19 \\
\hline River Raisin & Spring & GL18-10 & & $\mathrm{F}$ & 12.29 & 0.270 & 1.68 & 6.322 & 16450.34 & 112959.37 & 0.145630593 & 10.9 & 418.25 & 142.24 & 482.98 \\
\hline River Raisin & Spring & GL18-12 & & $\mathrm{F}$ & 9.72 & 0.159 & 1.16 & 4.904 & 9499.89 & 86616.02 & 0.10967821 & NA & NA & NA & NA \\
\hline River Raisin & Spring & GL18-14 & & M & 8.62 & 0.142 & 2.20 & 8.334 & 15354.5 & 110919.18 & 0.138429621 & 8.96 & 402.95 & 16.69 & 143.38 \\
\hline River Raisin & Spring & GL18-15 & & $\mathrm{F}$ & 8.33 & 0.312 & 1.50 & 7.147 & 8864.86 & 147106.13 & 0.060261663 & 7.9 & 421.3 & 107.02 & 132.4 \\
\hline River Raisin & Spring & GL18-16 & & $\mathrm{F}$ & 6.40 & 0.045 & 0.89 & 6.565 & 7639.47 & 90877.89 & 0.084063021 & 21.52 & 781.15 & 109.5 & 190.7 \\
\hline River Raisin & Spring & GL18-17 & & M & 10.06 & 0.297 & 1.82 & 7.062 & 9046.81 & 138809.14 & 0.065174455 & 13.85 & 441.8 & 16.47 & 327.94 \\
\hline River Raisin & Spring & GL18-18 & & M & 7.33 & 0.145 & 0.83 & NA & NA & NA & NA & 17.73 & 517.66 & 11.62 & 127.69 \\
\hline River Raisin & Spring & GL18-19 & 11 & M & 10.27 & 0.158 & 1.80 & 7.536 & 31383.85 & 63023.63 & 0.497969571 & 2.74 & 296.23 & 20.14 & 151.22 \\
\hline River Raisin & Spring & GL18-20 & & M & 10.80 & 0.305 & 4.63 & NA & NA & NA & \#VALUE! & 24.66 & 552.57 & 62.1 & 114.51 \\
\hline River Raisin & Spring & GL15A-1 & 7 & $\mathrm{~F}$ & 6.07 & 0.064 & 0.77 & 7.728 & 11678.6 & 188525.78 & 0.061946966 & 1.66 & 369.63 & 121.65 & 384.03 \\
\hline River Raisin & Spring & GL15A-2 & 7 & M & 5.99 & 0.118 & 0.96 & 7.276 & 11445.72 & 180641.45 & 0.063361537 & 7.93 & 456.98 & 5.17 & 203.33 \\
\hline River Raisin & Spring & GL15A-3 & & $\mathrm{F}$ & 5.52 & 0.051 & 1.08 & 6.664 & 11179.33 & 124979.94 & 0.089448995 & 18.97 & 1004.56 & 15.29 & 3.03 \\
\hline River Raisin & Spring & GL15A-5 & 10 & $\mathrm{~F}$ & 11.35 & 0.397 & 2.36 & NA & NA & NA & NA & 7.56 & 349.04 & 65.74 & 214.98 \\
\hline River Raisin & Spring & GL15A-6 & & $\mathrm{F}$ & 12.49 & 0.071 & 2.09 & NA & NA & NA & NA & 2.01 & 379.63 & 120.39 & 321.19 \\
\hline River Raisin & Spring & GL15A-7 & & $\mathrm{F}$ & 8.58 & 0.386 & 3.60 & 7.791 & 11216.16 & 90399.65 & 0.124073047 & 5.21 & 605.76 & 139.76 & 411.28 \\
\hline River Raisin & Spring & GL15A-13 & & M & 5.20 & 0.041 & 0.45 & 9.027 & 15669.96 & 99270.8 & 0.157850647 & NA & NA & NA & NA \\
\hline River Raisin & Spring & GL15A-20 & & M & 8.43 & 0.314 & 3.67 & 7.662 & 9572.8 & 158260.91 & 0.060487457 & 15.18 & 783.59 & 41.45 & 314.48 \\
\hline St. Louis Upper Estuary & Fall & GL2E-51 & 6 & $\mathrm{~F}$ & 5.07 & 0.147 & 0.70 & 5.676 & 8786.45 & 62724.29 & 0.140080502 & 10.25 & 245.03 & 4 & 114.69 \\
\hline St. Louis Upper Estuary & Fall & GL2E-52 & 9 & $\mathrm{~F}$ & 5.62 & 0.055 & 0.52 & 11.371 & 15455.57 & 72701.13 & 0.212590506 & 2.68 & 188.92 & 42.29 & 207.46 \\
\hline St. Louis Upper Estuary & Fall & GL2E-53 & 6 & M & 6.00 & 0.202 & 2.17 & 8.147 & 10145.38 & 151211.72 & 0.067093873 & 5.2 & 544.82 & 13.06 & 108.1 \\
\hline St. Louis Upper Estuary & Fall & GL2E-55 & 6 & M & 5.63 & 0.014 & 0.37 & 9.215 & 12961.24 & 79677.06 & 0.162672167 & 2.45 & 261.65 & 8.09 & 208.12 \\
\hline St. Louis Upper Estuary & Fall & GL2E-56 & 7 & M & 5.24 & 0.090 & 0.49 & 10.303 & 14842.65 & 103025.51 & 0.144067717 & 9.29 & 1223.44 & 23.92 & 247 \\
\hline St. Louis Upper Estuary & Fall & GL2E-57 & 8 & M & 6.39 & 0.135 & 0.80 & 9.585 & 16343.42 & 128772.63 & 0.126916877 & 6.28 & 230.98 & 6.28 & 293.75 \\
\hline St. Louis Upper Estuary & Fall & GL2E-58 & 8 & $\mathrm{~F}$ & 7.52 & 0.479 & 1.09 & 8.61 & 13253.83 & 71969.6 & 0.184158728 & 2.23 & 255.82 & 46.08 & 166.57 \\
\hline St. Louis Upper Estuary & Fall & GL2E-59 & 6 & M & 4.35 & 0.006 & 0.25 & 6.29 & 7368.13 & 108743.11 & 0.067757212 & 11.56 & 273.02 & 7.4 & 89.03 \\
\hline St. Louis Upper Estuary & Fall & GL2E-60 & 8 & $\mathrm{~F}$ & 5.15 & 0.167 & 0.70 & 6.047 & 8359.94 & 94545.93 & 0.088421998 & 3.34 & 206.68 & 6.44 & 62.23 \\
\hline St. Louis Upper Estuary & Fall & GL2E-61 & 6 & M & 5.77 & 0.013 & 0.40 & 10.057 & 15324.18 & 48162.73 & 0.31817507 & 1.62 & 210.4 & 10.29 & 121.62 \\
\hline St. Louis Upper Estuary & Fall & GL2E-62 & 6 & $\mathrm{~F}$ & 4.97 & 0.084 & 0.42 & NA & 23121.08 & 63952.85 & 0.361533223 & 6.32 & 254.71 & 76.73 & 364.24 \\
\hline St. Louis Upper Estuary & Fall & GL2E-63 & 7 & $\mathrm{~F}$ & 3.56 & 0.117 & 0.30 & 10.012 & 13667.24 & 84448.75 & 0.161840643 & 9.56 & 295.14 & 14.34 & 169.43 \\
\hline St. Louis Upper Estuary & Fall & GL2E-66 & 9 & M & 6.70 & 0.075 & 0.96 & 13.871 & 19363.55 & 76801.85 & 0.252123484 & 8.3 & 278.7 & 6.34 & 419.77 \\
\hline St. Louis Upper Estuary & Fall & GL2E-67 & 10 & $\mathrm{~F}$ & 5.47 & 0.133 & 0.38 & 10.289 & 15258.13 & 58464.29 & 0.260982046 & 9.98 & 348.08 & 74.63 & 270.32 \\
\hline St. Louis Upper Estuary & Fall & GL2E-68 & 7 & $\mathrm{~F}$ & 5.33 & 0.105 & 0.52 & NA & NA & NA & NA & 6.56 & 621.91 & 34.02 & 387.97 \\
\hline St. Louis Upper Estuary & Fall & GL2E-69 & 7 & $\mathrm{~F}$ & 9.38 & 0.237 & 1.06 & 6.661 & 13035.25 & 116580.81 & 0.111812999 & 7.46 & 1729.44 & 18.76 & 181.29 \\
\hline St. Louis Upper Estuary & Fall & GL2E-70 & 10 & M & 5.83 & 0.128 & 0.48 & 11.273 & 20544.81 & 81250.68 & 0.252857084 & 1.22 & 222.23 & 14.32 & 205.21 \\
\hline St. Louis Middle Estuan & Fall & GL2D-51 & 9 & $\mathrm{~F}$ & 6.00 & 0.239 & 0.31 & 9.053 & 16405.13 & 161538.58 & 0.101555492 & 1 & 173.35 & 65.61 & 176.46 \\
\hline St. Louis Middle Estuar? & Fall & GL2D-52 & 9 & $\mathrm{~F}$ & 5.71 & 0.107 & 0.36 & 10.928 & 15412.55 & 41160.76 & 0.374447654 & 4.77 & 135.03 & 30.82 & 62.89 \\
\hline St. Louis Middle Estuar) & Fall & GL2D-53 & 9 & M & 5.09 & 0.087 & 0.48 & 14.008 & 22987.43 & 51162.67 & 0.449300828 & 6.75 & 549.58 & 12.58 & $3 \quad 1405.66$ \\
\hline St. Louis Middle Estuar? & Fall & GL2D-55 & 8 & $\mathrm{~F}$ & 5.75 & 0.060 & 0.42 & 13.838 & 20027.72 & 127042.17 & 0.157646237 & 6.37 & 298.45 & 72.5 & 245.55 \\
\hline St. Louis Middle Estuarn & Fall & GL2D-56 & 7 & M & 5.77 & 0.113 & 0.45 & 15.077 & 21898.66 & 58531.31 & 0.374135826 & 3.14 & 433.75 & 19.48 & 925.87 \\
\hline St. Louis Middle Estuar? & Fall & GL2D-57 & 7 & $\mathrm{~F}$ & 4.99 & 0.111 & 0.40 & 14.305 & 22078.56 & 199663.67 & 0.110578755 & 5.12 & 372.02 & 61.16 & 372.02 \\
\hline St. Louis Middle Estuar) & Fall & GL2D-58 & 5 & $\mathrm{~F}$ & 6.78 & 0.579 & 1.14 & 13.505 & 20451.25 & 179853.78 & 0.113710426 & 5.9 & 398.15 & 62.57 & 608.17 \\
\hline St. Louis Middle Estuan? & Fall & GL2D-60 & 7 & $\mathrm{~F}$ & 10.20 & 0.174 & 0.56 & 17.222 & 18140.88 & 60807.19 & 0.298334457 & 1.26 & 396.45 & 48.69 & 736.62 \\
\hline St. Louis Middle Estuar) & Fall & GL2D-61 & 7 & M & 10.98 & 0.531 & 1.24 & 11.412 & 15588.01 & 77807.56 & 0.200340558 & 6.91 & 563.14 & 55.38 & 672.85 \\
\hline St. Louis Middle Estuan? & Fall & GL2D-62 & 5 & M & 9.14 & 0.252 & 0.73 & 15.318 & 25108.96 & 103869.57 & 0.241735477 & 3.3 & 532.77 & 55.87 & 840.69 \\
\hline St. Louis Middle Estuar) & Fall & GL2D-63 & 7 & M & 6.89 & 0.436 & 0.77 & 16.773 & 23077.66 & 93902.09 & 0.245763007 & 5.44 & 564.22 & 11.61 & 593.83 \\
\hline St. Louis Middle Estuan & Fall & GL2D-64 & 8 & $\mathrm{~F}$ & 8.64 & 0.074 & 1.13 & 12.53 & 20251.62 & 101559.48 & 0.199406496 & 17.4 & 550.87 & 47.39 & 623.57 \\
\hline St. Louis Middle Estuarn & Fall & GL2D-67 & 9 & $\mathrm{~F}$ & 5.98 & 0.107 & 0.43 & 14.478 & 17999.73 & 140051.17 & 0.128522525 & 4.7 & 477.88 & 56.07 & 418.73 \\
\hline
\end{tabular}




\section{Brown bullhead}

\begin{tabular}{|c|c|c|c|c|c|c|c|c|c|c|c|c|c|}
\hline Location & Season & Fish_ID & Age & Sex & TECH & Percent & Ratio & TSH & T3 & T4 & TH_ratio & THR $\alpha$ & THR $\beta$ \\
\hline Detroit River & Spring & GL4-82 & 5 & $M$ & 5.62 & 0.073 & 0.68 & 6.355 & 7660.31 & 56427.19 & 0.135755653 & 19.79 & 5.59 \\
\hline Detroit River & Spring & GL4-83 & 6 & $\mathrm{~F}$ & 6.66 & 0.165 & 0.72 & 3.816 & 9659.99 & 79698.72 & 0.121206338 & 13.5 & 10.95 \\
\hline Detroit River & Spring & GL4-84 & 6 & $M$ & 10.88 & 0.318 & 2.22 & 3.537 & 281.46 & 86273.28 & 0.003262424 & 14.88 & 6.93 \\
\hline Detroit River & Spring & GL4-86 & 4 & $M$ & 7.57 & 0.183 & 0.98 & 4.491 & 5496.81 & 64686.23 & 0.084976509 & 17.62 & 11.63 \\
\hline Detroit River & Spring & GL4-87 & 10 & $\mathrm{~F}$ & 8.06 & 0.248 & 1.50 & 3.627 & 5428.33 & 78362.11 & 0.069272382 & 1.92 & 7.09 \\
\hline Detroit River & Spring & GL4-88 & 7 & $\mathrm{~F}$ & 7.94 & 0.088 & 1.88 & 4.34 & 2729.68 & 74510.9 & 0.03663464 & 4.66 & 10.1 \\
\hline Detroit River & Spring & GL4-89 & 6 & M & 10.08 & 0.626 & 0.69 & 5.262 & 6434.8 & 67832.32 & 0.094863334 & 13.61 & 4.23 \\
\hline Detroit River & Spring & GL4-91 & 12 & $\mathrm{~F}$ & 9.34 & 0.150 & 1.29 & 4.378 & 2556.19 & 154325.08 & 0.016563672 & 11.23 & 5.32 \\
\hline Detroit River & Spring & GL4-92 & 5 & $M$ & 11.38 & 0.559 & 7.65 & 4.298 & 6403.71 & 81533.54 & 0.078540807 & 18.8 & 11.03 \\
\hline Detroit River & Spring & GL4-93 & 5 & $\mathrm{~F}$ & 8.88 & 0.065 & 1.10 & 4.484 & 5218.04 & 88497.08 & 0.058962849 & 11.29 & 9.51 \\
\hline Detroit River & Spring & GL4-94 & 7 & $M$ & 9.63 & 0.279 & 1.96 & 4.242 & 5660.91 & 48389.19 & 0.116987079 & 5.49 & 5.49 \\
\hline Detroit River & Spring & GL4-95 & 5 & $M$ & 10.56 & 0.440 & 2.19 & 5.226 & 5448.19 & 73024.58 & 0.074607618 & 15.82 & 10.57 \\
\hline Detroit River & Spring & GL4-96 & 12 & $M$ & 11.37 & 0.290 & 2.95 & 3.699 & 891.08 & 80906.84 & 0.011013655 & 15.12 & 7.92 \\
\hline Detroit River & Spring & GL4-97 & 5 & M & 8.53 & 0.208 & 1.80 & 4.167 & 4977.44 & 88474.65 & 0.056258375 & 18.48 & 15.05 \\
\hline Detroit River & Spring & GL4-98 & 8 & M & 8.67 & 0.202 & 1.78 & 3.356 & 4718.13 & 203069.97 & 0.023234011 & 21.29 & 18.52 \\
\hline Detroit River & Spring & GL4-99 & 5 & $M$ & 10.41 & 0.627 & 2.42 & NA & NA & NA & NA & 12.19 & 4.05 \\
\hline Detroit River & Spring & GL4-100 & 5 & M & 8.06 & 0.349 & 0.87 & 4.235 & 3311.79 & 88862.39 & 0.037268748 & 30.49 & 9.92 \\
\hline Rochester_Irondequoit & Spring & GL14A-2 & 8 & $\mathrm{~F}$ & 8.67 & 0.544 & 4.07 & 4.866 & 6907.6 & 133294.79 & 0.05182198 & 5.69 & 17.75 \\
\hline Rochester_Irondequoit & Spring & GL14A-3 & 9 & M & 11.45 & 0.453 & 4.27 & 4.755 & 10479.68 & 241385.19 & 0.04341476 & 13.14 & 20.33 \\
\hline Rochester_Irondequoit & Spring & GL14A-4 & 7 & $M$ & 14.36 & 0.318 & 2.97 & 6.504 & 13348.66 & 67773.99 & 0.19695845 & 19.01 & 16.71 \\
\hline Rochester_Irondequoit & Spring & GL14A-5 & 17 & $M$ & 9.04 & 0.476 & 3.23 & 4.583 & 5212.76 & 64336.66 & 0.081023168 & 17.84 & 28.69 \\
\hline Rochester_Irondequoit & Spring & GL14A-8 & 8 & M & 10.14 & 0.505 & 2.23 & 7.134 & 8245.76 & 74782.16 & 0.110263731 & 24.45 & 29.36 \\
\hline Rochester_Irondequoit & Spring & GL14A-9 & 7 & $M$ & 10.97 & 0.311 & 5.40 & 10.066 & 19683.79 & 97402.16 & 0.202087818 & 7.11 & 11.48 \\
\hline Rochester_Irondequoit & Spring & GL14A-11 & 7 & $\mathrm{~F}$ & 7.74 & 0.326 & 1.18 & 5.074 & 12574.59 & 81921.88 & 0.15349489 & 15.12 & 7.79 \\
\hline Rochester_Irondequoit & Spring & GL14A-12 & 7 & $\mathrm{~F}$ & 10.03 & 0.412 & 3.25 & 4.155 & 5382.84 & 105251.47 & 0.051142659 & 9.68 & 19.76 \\
\hline Rochester_Irondequoit & Spring & GL14A-13 & 7 & $M$ & 8.86 & 0.687 & 3.42 & 8.724 & 13449.6 & 84600.78 & 0.158977258 & 26.43 & 23.84 \\
\hline Rochester_Irondequoit & Spring & GL14A-14 & 6 & $\mathrm{~F}$ & 10.27 & 0.234 & 2.28 & 5.294 & 6769.03 & 116964.22 & 0.057872655 & 8.41 & 6.4 \\
\hline Rochester_Irondequoit & Spring & GL14A-15 & 7 & $\mathrm{~F}$ & 11.77 & 0.263 & 3.77 & 4.567 & 5472.06 & 193445.13 & 0.028287401 & 8.22 & 8.22 \\
\hline Rochester_Irondequoit & Spring & GL14A-16 & 11 & $\mathrm{~F}$ & 8.64 & 0.375 & 2.75 & 3.888 & 3466.6 & 82667.97 & 0.041934016 & 27.37 & 13.25 \\
\hline Rochester_Irondequoit & Spring & GL14A-17 & 7 & $\mathrm{~F}$ & 12.32 & 0.478 & 10.31 & 4.97 & 6786.7 & 84637.71 & 0.080185298 & 7.94 & 9.89 \\
\hline Rochester_Irondequoit & Spring & GL14A-20 & ND & M & 9.69 & 0.153 & 2.68 & 4.759 & 12555.99 & 94133.69 & 0.133384658 & 12.94 & 25.33 \\
\hline Rochester_LongPond & Spring & GL14B-2 & 7 & $M$ & 11.76 & 0.685 & 2.82 & 4.217 & 7480.47 & 79508.81 & 0.094083536 & 21.81 & 2.14 \\
\hline Rochester_LongPond & Spring & GL14B-3 & ND & $M$ & 10.67 & 0.247 & 2.84 & 5.582 & 6156.03 & 55123.64 & 0.111676769 & 26.95 & 3.58 \\
\hline Rochester_LongPond & Spring & GL14B-4 & 6 & M & 7.31 & 0.623 & 1.97 & 3.543 & 2220.22 & 106761.38 & 0.020796097 & 24.72 & 13.66 \\
\hline Rochester_LongPond & Spring & GL14B-5 & 9 & M & 9.74 & 0.520 & 2.73 & 4.533 & 6952.1 & 171821.79 & 0.040461108 & 23.52 & 3.03 \\
\hline Rochester_LongPond & Spring & GL14B-9 & 9 & M & 7.45 & 0.543 & 1.96 & 3.914 & 2743.74 & 83091.83 & 0.033020575 & 23.75 & 8.89 \\
\hline Rochester_LongPond & Spring & GL14B-15 & 6 & M & 9.73 & 0.388 & 2.03 & 3.961 & 7740.78 & 77692.27 & 0.09963385 & 13.18 & 13.18 \\
\hline Rochester_LongPond & Spring & GL14B-18 & 8 & M & 10.25 & 0.337 & 2.03 & 3.669 & 1125.9 & 64821.27 & 0.017369299 & 31.64 & 8.09 \\
\hline
\end{tabular}

